\title{
Multiband Planar Inverted-F Antenna with Independent Operating Bands Control for Mobile Handset Applications
}

\author{
Mustapha El Halaoui, ${ }^{1}$ Abdelmoumen Kaabal, ${ }^{1}$ Hassan Asselman, ${ }^{1}$ \\ Saida Ahyoud, ${ }^{2}$ and Adel Asselman ${ }^{1}$ \\ ${ }^{1}$ Optics and Photonics Team, Faculty of Sciences, Abdelmalek Essaadi University, P.O. Box 2121, Tetouan, Morocco \\ ${ }^{2}$ Information Technology and Systems Modeling Team, Faculty of Sciences, Abdelmalek Essaadi University, P.O. Box 2121, \\ Tetouan, Morocco
}

Correspondence should be addressed to Mustapha El Halaoui; mustapha.halaoui@gmail.com

Received 19 September 2016; Revised 28 December 2016; Accepted 13 February 2017; Published 20 March 2017

Academic Editor: Ikmo Park

Copyright (C) 2017 Mustapha El Halaoui et al. This is an open access article distributed under the Creative Commons Attribution License, which permits unrestricted use, distribution, and reproduction in any medium, provided the original work is properly cited.

A new compact multiband PIFA (Planar Inverted-F Antenna) for mobile handset is proposed in this article. The proposed PIFA has a simple geometry with four slots integrated in the radiating patch and ground plane. The PIFA occupies a small volume of $51 \times 14 \times$ $7.2 \mathrm{~mm}^{3}$ and is placed on the top portion of mobile phone. The optimized PIFA is worked in the $790 \mathrm{MHz}$ band $(737-831 \mathrm{MHz})$, the $1870 \mathrm{MHz}$ band (1794-1977 MHz), the $2550 \mathrm{MHz}$ band (2507-2615 MHz), and the $3400 \mathrm{MHz}$ band (3341-3545 MHz), to cover LTE700, LTE800, DCS1800, PCS1900, LTE1800, LTE1900, LTE2500, and WIMAX3400 bands. Each of the four operating bands can be controlled independently by the variation of a single parameter of the proposed design, with a wide control range. An omnidirectional radiation pattern to each resonant frequency is obtained with a maximum gain of $2.15 \mathrm{dBi}$ at $790 \mathrm{MHz}, 3.99 \mathrm{dBi}$ at $1870 \mathrm{MHz}, 4.57 \mathrm{dBi}$ at $2550 \mathrm{MHz}$, and $6.43 \mathrm{dBi}$ at $3400 \mathrm{MHz}$. The proposed PIFA is studied in the free space and in the presence of other mobile phone components such as the battery, LCD (liquid crystal display), camera, microphone, speaker, buttons, and a plastic housing. The distribution of specific absorption rate for both European and American standards for each operating band and at various distances between the antenna and the human head is also studied.

\section{Introduction}

Recently, Long term Evolution (LTE) and Worldwide Interoperability for Microwave Access (WIMAX) are considered as new standards for the 4th-generation systems. Therefore, modern smart-phones must work in the cellular communication systems of the fourth generation, and then they must operate in the LTE and WIMAX frequencies bands. Thus, novel antenna solutions for mobile phone are required to be able to cover all the existing frequency bands $[1,2]$.

The antenna is the key component in mobile devices and plays an important role in the design of smart-phones. Therefore, antenna design with a small size and low cost and ability to operate in multiband for smart-phones is usually a challenge. The planar inverted-F antenna (PIFA) has become the most popular antenna for mobile phones, because it has many outstanding advantages like compact structure, light weight, small size, low manufacturing cost, being integrated with other handset components, good electrical performance, good radiation characteristics, high gain, and low value of the specific absorption rate (SAR), and so forth $[3,4]$. In addition, several works of literature have proposed miniature structures of multiband PIFA by inserting the slots in the radiating patch and in the ground plane [5-10].

The narrow bandwidth is one of the disadvantages of using PIFA in mobile phones. Therefore, many researchers have studied the improvement of the bandwidth of PIFA by using different techniques [11-19]. Another approach to solving this problem is the independent control of resonant frequency for multiband PIFA. This approach is based on the multiband antenna and the parametric study of each antenna parameter on the resonance frequencies. However, this technique is very challenging, because the PIFA parameters have a complex relationship between them; therefore when the 
TABLE 1: Comparison of the proposed PIFA with other literature PIFAs with independent control of frequency bands.

\begin{tabular}{|c|c|c|c|c|}
\hline Structure & $\begin{array}{l}\text { Frequency band with } \\
\text { independent control }\end{array}$ & Antenna size (mm3) & Gain (dBi) & Radiation efficiency (\%) \\
\hline $\begin{array}{l}\text { The } \\
\text { proposed } \\
\text { one }\end{array}$ & $\begin{array}{c}0.79 \mathrm{GHz}, 1.87 \mathrm{GHz}, 2.55 \mathrm{GHZ} \\
\text { and } 3.4 \mathrm{GHz} \text { bands }\end{array}$ & $51 \times 14 \times 4$ & $\begin{array}{c}2.15 \text { at } 0.79 \mathrm{GHz}, 3.99 \text { at } \\
1.87 \mathrm{GHz}, 4.57 \text { at } 2.55 \mathrm{GHz} \text {, and } \\
6.43 \text { at } 3.4 \mathrm{GHz}\end{array}$ & $\begin{array}{c}63 \text { at } 0.79 \mathrm{GHz}, 72 \text { at } \\
1.87 \mathrm{GHz}, 71 \text { at } 2.55 \mathrm{GHz}, \\
\text { and } 80.25 \text { at } 3.4 \mathrm{GHz}\end{array}$ \\
\hline$[20]$ & $\begin{array}{c}2.09 \mathrm{GHz}, 3.74 \mathrm{GHz} \text {, and } 5.1 \mathrm{GHz} \\
\text { bands }\end{array}$ & $27.57 \times 25.6 \times 3.75$ & $\begin{array}{c}2.14 \text { at } 2.09 \mathrm{GHz}, 2.41 \mathrm{at} \\
3.74 \mathrm{GHz} \text {, and } 5.00 \text { at } 5.1 \mathrm{GHz}\end{array}$ & $\begin{array}{c}70 \text { at } 2.09 \mathrm{GHz}, 60.3 \text { at } \\
3.74 \mathrm{GHz} \text {, and } 66 \text { at } 5.1 \mathrm{GHz}\end{array}$ \\
\hline [21] & $\begin{array}{c}0.92 \mathrm{GHz}, 1.8 \mathrm{GHz} \text {, and } 2.63 \mathrm{GHz} \\
\text { bands }\end{array}$ & $105 \times 30 \times 9$ & $\begin{array}{c}1.91 \text { at } 0.92 \mathrm{GHz}, 2.93 \text { at } 1.8 \mathrm{GHz} \\
\text { and } 1.48 \text { at } 2.63 \mathrm{GHz}\end{array}$ & $\begin{array}{c}80 \text { at } 0.92 \mathrm{GHz}, 80 \text { at } \\
1.8 \mathrm{GHz} \text {, and } 90 \text { at } 2.63 \mathrm{GHz}\end{array}$ \\
\hline$[22]$ & $\begin{array}{c}1.8 \mathrm{GHz}, 2.45 \mathrm{GHz}, 3.5 \mathrm{GHz} \text {, and } \\
5.2 \mathrm{GHz} \text { bands }\end{array}$ & $22 \times 33.5 \times 8.8$ & $\begin{array}{c}2.3 \text { at } 1.8 \mathrm{GHz}, 2.2 \text { at } 2.45 \mathrm{GHz}, 1.7 \\
\text { at } 3.5 \mathrm{GHz} \text {, and } 4.47 \text { at } 5.2 \mathrm{GHz}\end{array}$ & - \\
\hline$[23]$ & $\begin{array}{c}0.9 \mathrm{GHz}, 1.75 \mathrm{GHz}, 2.15 \mathrm{GHz} \\
2.45 \mathrm{GHz}, 3.5 \mathrm{GHz} \text {, and } 5.2 \mathrm{GHz} \\
\text { bands }\end{array}$ & $40 \times 20 \times 8$ & $\begin{array}{c}1.85 \text { at } 0.9 \mathrm{GHz}, 2.21 \text { at } 1.75 \mathrm{GHz} \\
3.79 \text { at } 2.15 \mathrm{GHz}, 3.96 \text { at } \\
2.45 \mathrm{GHz}, 2.34 \text { at } 3.5 \mathrm{GHz} \text {, and } \\
4.6 \text { at } 5.2 \mathrm{GHz}\end{array}$ & $\begin{array}{c}82 \text { at } 0.9 \mathrm{GHz}, 79 \text { at } \\
1.75 \mathrm{GHz}, 81 \text { at } 2.15 \mathrm{GHz}, 90 \\
\text { at } 2.45 \mathrm{GHz}, 90 \text { at } 3.5 \mathrm{GHz} \text {, } \\
\text { and } 91 \text { at } 5.2 \mathrm{GHz}\end{array}$ \\
\hline
\end{tabular}

antenna parameter is changed, all other frequency bands are affected [20]. Some works have been done to achieve frequency independent control for a multiband PIFA. For example, in [20], PIFA was studied to independently control three resonant frequencies for UMTS/WIMAX/WLAN. In [21], a triband PIFA with a relatively large size of $105 \times 30$ $\times 9 \mathrm{~mm}^{3}$ was studied to control three bands GSM/DCS/SDMB. In [22], a coplanar waveguide PIFA was presented with independent control of resonance frequencies by integrating the slots in the radiating patch and the ground plane. However, the structure of the PIFA could not provide a wide independent control for the frequency bands. In [23], a multiband PIFA which covers ten frequency bands was proposed. Most of the frequency bands can be adjusted independently without seriously affecting the rest of the resonant frequencies. However, the control ranges of the frequency bands were limited to only few percentages.

In this article, a multiband PIFA for mobile handset is proposed; it has a simple geometry which formed by integrating the four slots in the radiating patch and the ground plane. The proposed PIFA covers four service bands: LTE700, LTE1800, LTE2500, and WIMAX3400. The proposed PIFA consists in a new version of the dual band GSM/DCS PIFA presented in [24] featuring a smaller size antenna by integrating $\Omega$-shaped slot in the radiating patch and adding two other operating bands by integrating two other slots. The PIFA is composed of four integrated slots to generate four operating bands. Therefore, the main slot is the $\Omega$-shaped slot (a combination of circle-shaped slot and rectangular slot) which presents smaller antenna size compared with the one in [24] and generates the two lower bands. And the two additional slots (integrated in the radiating patch and in the ground plane) with a rectangular shape are used to control the upper two bands. The proposed multiband PIFA has the ability to independently control the frequency bands by varying the dimensions of the integrated slots in the structure. The presented PIFA gives omnidirectional radiation patterns and an acceptable gain for mobile phone applications. The PIFA is integrated in the handset to test its performance in the presence of other mobile phone components. The SAR values obtained are less than the specific limit for both European and American standards and for each frequency band. Table 1 shows a comparison of the proposed PIFA with other PIFAs proposed in recent works. This comparison is made in terms of operating band with independent control, antenna size, gain, and radiation efficiency. The proposed PIFA has the capability of wide independent control of the four frequency bands. The antenna gain and radiation efficiency are also improved apparently.

The antenna configuration, parametric studies, independent control, and current distribution are presented in Section 2, while the simulated and measured results of the reflection coefficient, radiation pattern, and gain are presented in Section 3. The last sections will be devoted to the integration of the antenna in the handset and the SAR results.

\section{Configuration of the Proposed PIFA}

2.1. Antenna Geometry. Figure 1 shows the structure of the multiband PIFA for mobile phones to 4th-generation wireless communications. The proposed PIFA is composed of the following four main parts: a radiating patch designed on FR4 substrate (thickness $h s=1.6 \mathrm{~mm}$, dielectric constant $\varepsilon_{r}$ $=4.4$, and the loss tangent $\tan \delta=0.025$ ) (Figure $1(\mathrm{~b})$ ), a ground plane which has the form of a mobile phone PCB (Printed Circuit Board) (Figure 1(a)), a short-circuit plate linked between the ground plane and the radiating patch, and a feed mechanism in the form of a 50-SMA connector (Figure 1(c)). The proposed PIFA is mounted on the top edge of the mobile phone PCB and occupies a volume of $51 \times 14$ $\times 4 \mathrm{~mm}^{3}$. The ground plane is printed on the back of the FR4 substrate and occupies a volume of $51 \times 110 \mathrm{~mm}^{2}$. The locations of the feeding pin and shorting strip are shown in Figure 1(c). To reduce the antenna size and achieve a multiband antenna, four slots (circle-shaped slot, slot \#1, slot $\# 2$, and slot \#3) are integrated in the base PIFA. The design of the PIFA is optimized using the CST Microwave Studio, and 


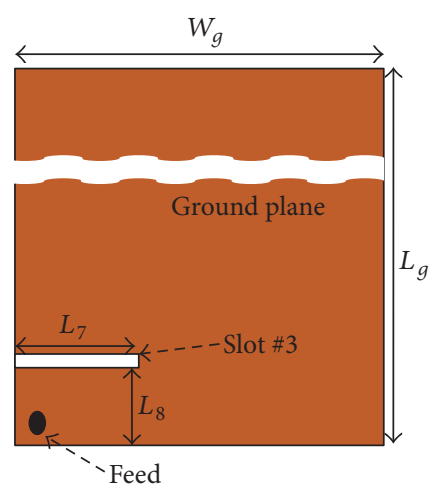

(a)

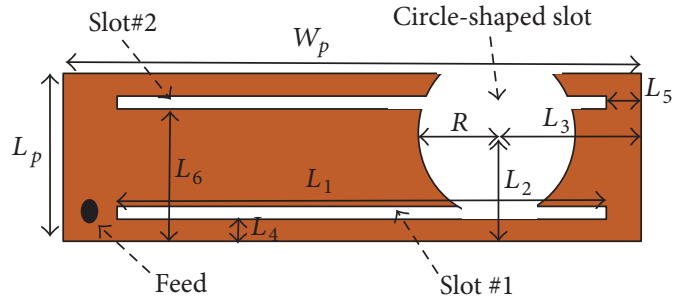

(b)

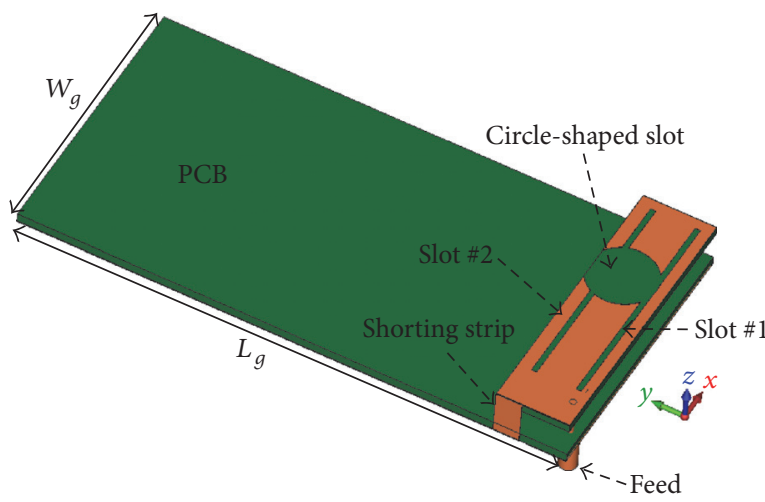

(c)

FIGURE 1: The geometry of the proposed PIFA: (a) ground plane, (b) radiating patch, and (c) the 3D view.

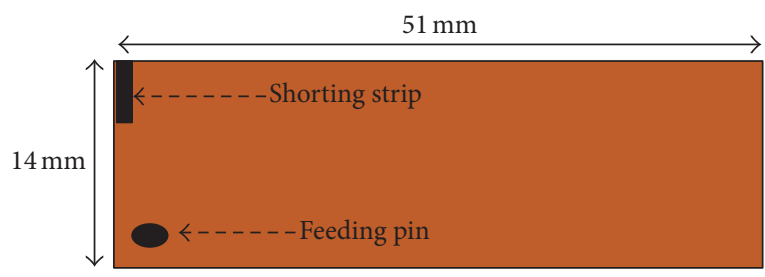

(a)

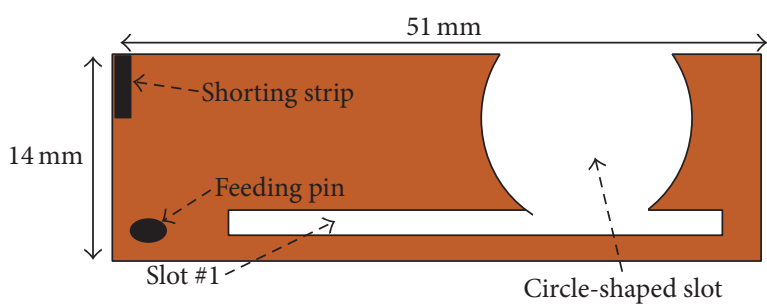

(c)

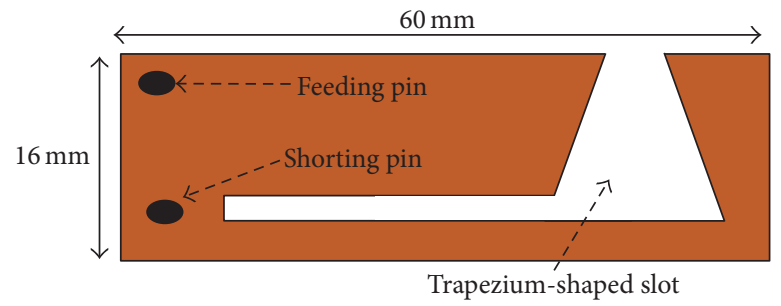

(b)

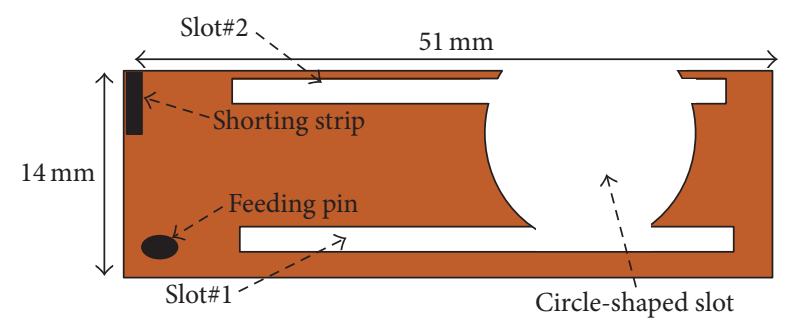

(d)

Figure 2: The evolution steps of the proposed PIFA: (a) Ant1, (b) Ant2, (c) Ant3, and (d) Ant4.

the optimized dimensions are as follows: $L_{g}=110 \mathrm{~mm}, W_{g}=$ $51 \mathrm{~mm}, L_{p}=14 \mathrm{~mm}, W_{p}=51 \mathrm{~mm}, R=7.6 \mathrm{~mm}, L_{1}=43 \mathrm{~mm}$, $L_{2}=8.4 \mathrm{~mm}, L_{3}=18 \mathrm{~mm}, L_{4}=1 \mathrm{~mm}, L_{5}=2 \mathrm{~mm}, L_{6}=11 \mathrm{~mm}$, $L_{7}=17 \mathrm{~mm}$, and $L_{8}=9 \mathrm{~mm}$.
2.2. Design Process. The design process of the multiband PIFA can be described using Figure 2 as follows. Ant1 is a basic PIFA with the same dimensions of the proposed antenna $51 \times 14 \times 4 \mathrm{~mm}^{3}$ (Figure 2(a)). Ant2 is obtained by adding 
TABLE 2: Independent control ranges in the four operating bands.

\begin{tabular}{lcccc}
\hline Parameter variation & Control range for band \#1 & Control range for band \#2 & Control range for band \#3 & Control range for band \#4 \\
\hline$R(6.5$ to $8.5 \mathrm{~mm})$ & No effect & $1676-2000 \mathrm{MHz}$ & No effect & No effect \\
$L_{1}(36$ to $49 \mathrm{~mm})$ & $745-885 \mathrm{MHz}$ & $1665-2113 \mathrm{MHz}$ & $2358-2915 \mathrm{MHz}$ & No effect \\
$L_{3}(10$ to $20 \mathrm{~mm})$ & No effect & $1448-2068 \mathrm{MHz}$ & $2500-2900 \mathrm{MHz}$ & No effect \\
$L_{4}(0.5$ to $4 \mathrm{~mm})$ & $745-1025 \mathrm{MHz}$ & $1735-2026 \mathrm{MHz}$ & $2509-3048 \mathrm{MHz}$ & No effect \\
$L_{6}(0.5$ to $6.5 \mathrm{~mm})$ & No effect & No effect & $2446-3080 \mathrm{MHz}$ & No effect \\
$L_{7}(15$ to $19 \mathrm{~mm})$ & No effect & No effect & No effect & $2880-4253 \mathrm{MHz}$ \\
\hline
\end{tabular}

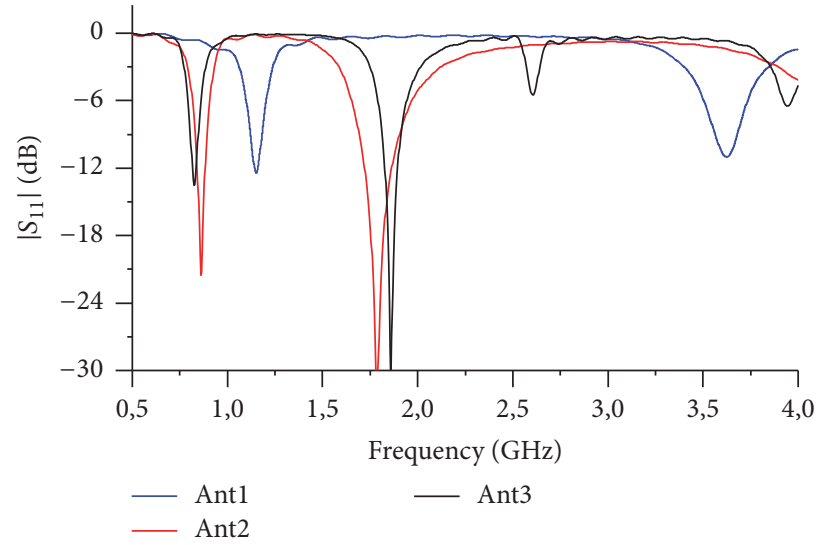

(a)

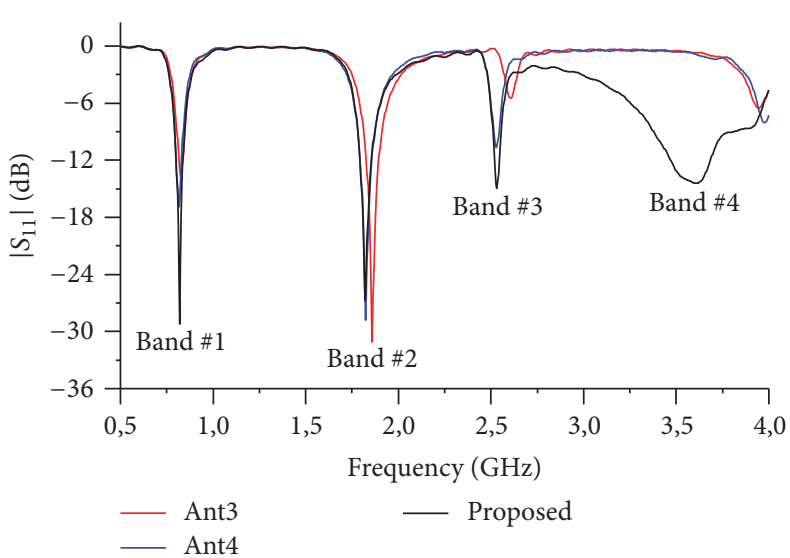

(b)

Figure 3: Comparison of simulated reflection coefficient for different antennas: (a) Ant1, Ant2, and Ant3 and (b) Ant3 and Ant4 and the proposed antenna.

a combination of a trapezoidal shaped slot and a rectangular slot in the radiating patch, as in Figure 2(b). Ant3 is obtained by replacing the trapezoidal shaped slot of Ant 2 by a circleshaped slot to form the $\Omega$-shaped slot (see Figure $2(\mathrm{c})$ ). To obtain a third operating band (band \#3), the radiating patch of the Ant3 has been modified by integrating the rectangular slot \#2 to form the Ant4 (Figure 2(d)). Finally, for the proposed antenna, slot \#3 is integrated in the ground plane (see Figure 1(a)) to generate a fourth operating band (band \#4).

Figure 3(a) shows the comparison between the reflection coefficients of the three antennas (Ant1, Ant2, and Ant3). When the trapezoidal shaped slot (Ant2) is integrated in the radiating patch, the first resonant frequency is shifted to lower frequencies, and the second resonant frequency is created at $1800 \mathrm{MHz}$. Note that the Antl size is $51 \times 14 \times$ $4 \mathrm{~mm}^{3}$ and the Ant 2 size is $60 \times 16 \times 4 \mathrm{~mm}^{3}$. Ant 3 with the $\Omega$-shaped slot can cover the same frequencies bands for Ant 2 with a smaller size about $51 \times 14 \times 4 \mathrm{~mm}^{3}$. Therefore, the $\Omega$-shaped slot presents miniaturization of the antenna size by $15 \%$. Figure 3 (b) shows the comparison between the simulated reflection coefficients of the proposed PIFA and the two antennas (Ant3, Ant4). For Ant3, it only generates two resonant frequencies at $800 \mathrm{MHz}$ and $1800 \mathrm{MHz}$. Ant 4 can generate a third operating band (band \#3) by integrating slot $\# 2$ in the radiating patch. Finally, by embedding slot \#3 in the ground plane (as show in Figure 1(a)) the proposed PIFA can operate in the fourth operating band (band \#4) at $3400 \mathrm{MHz}$.
2.3. Parametric Studies and Independent Control. Implementing multiband antennas for mobile handsets applications is not easy by using a simple structure, which contains few strips and slots. On the other hand, a complex structure contains several parameters of the antenna and controls these parameters for the desired services which increases the design's complexity. To design a multiband antenna for mobile handsets, it is desirable to have an independent control of resonant frequencies. This study concentrates on the independent control on frequencies bands, to see the effects of the critical parameters of the proposed PIFA design without changing the size of the radiating patch or ground plane. The geometrical parameters to be studied are the radius of the circle-shaped slot $(R)$, the length of slots \#1 and \#2 $\left(L_{1}\right)$, the position of the circle-shaped slot along the $x$-axis $\left(L_{3}\right)$, the position of slot \#1 along the $y$-axis $\left(L_{4}\right)$, the position of slot $\# 2$ along $y$-axis $\left(L_{6}\right)$, and the length of slot \#3 $\left(L_{7}\right)$. When a parameter is studied, the other parameters are kept constant.

The reflection coefficient result with the radius $R$ of the circle-shaped slot varies from $6.5 \mathrm{~mm}$ to $8.5 \mathrm{~mm}$ are shown in Figure 4(a). From this figure, we notice that, with the increase of $R$, the central frequencies in the second frequency band (band \#2) are shifted towards higher frequencies. Therefore, the resonant frequency of band \#2 may be effectively controlled by adjusting the radius $R$ of the circle-shaped slot to operate at any desired frequency band. Band \#2 can be controlled between 1676 and $2001 \mathrm{MHz}$, as shown in the Table 2 . 

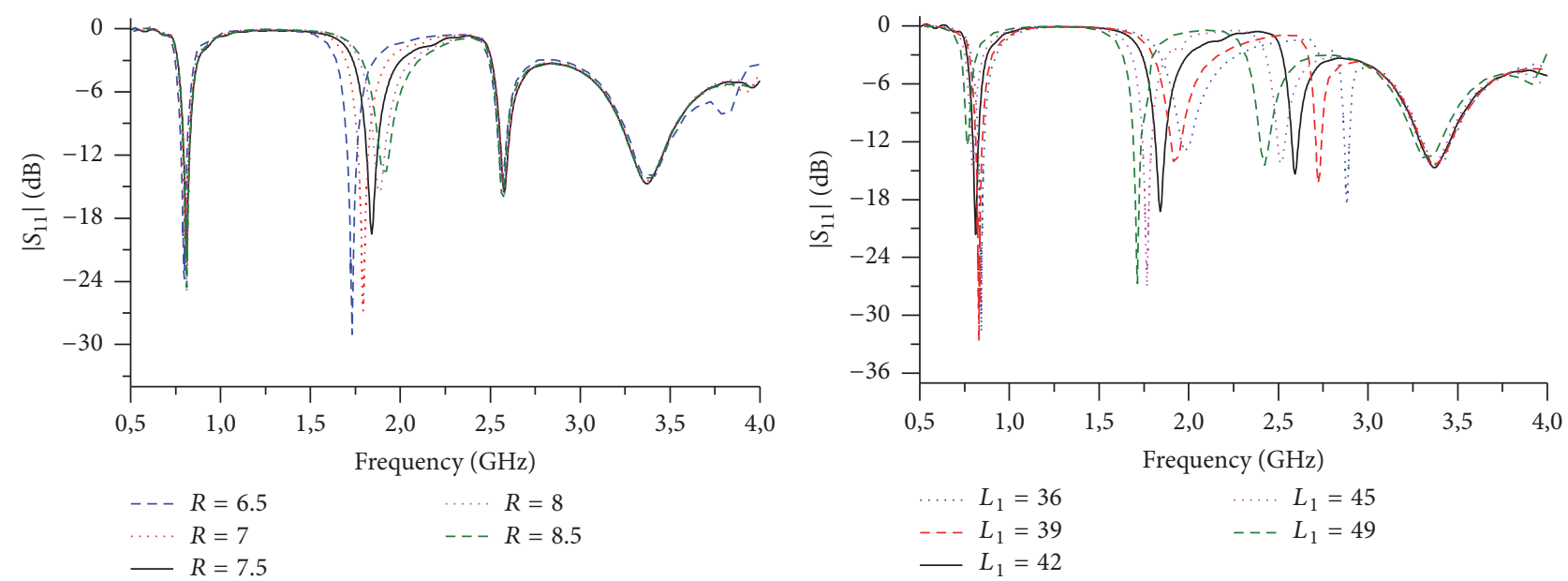

(a)
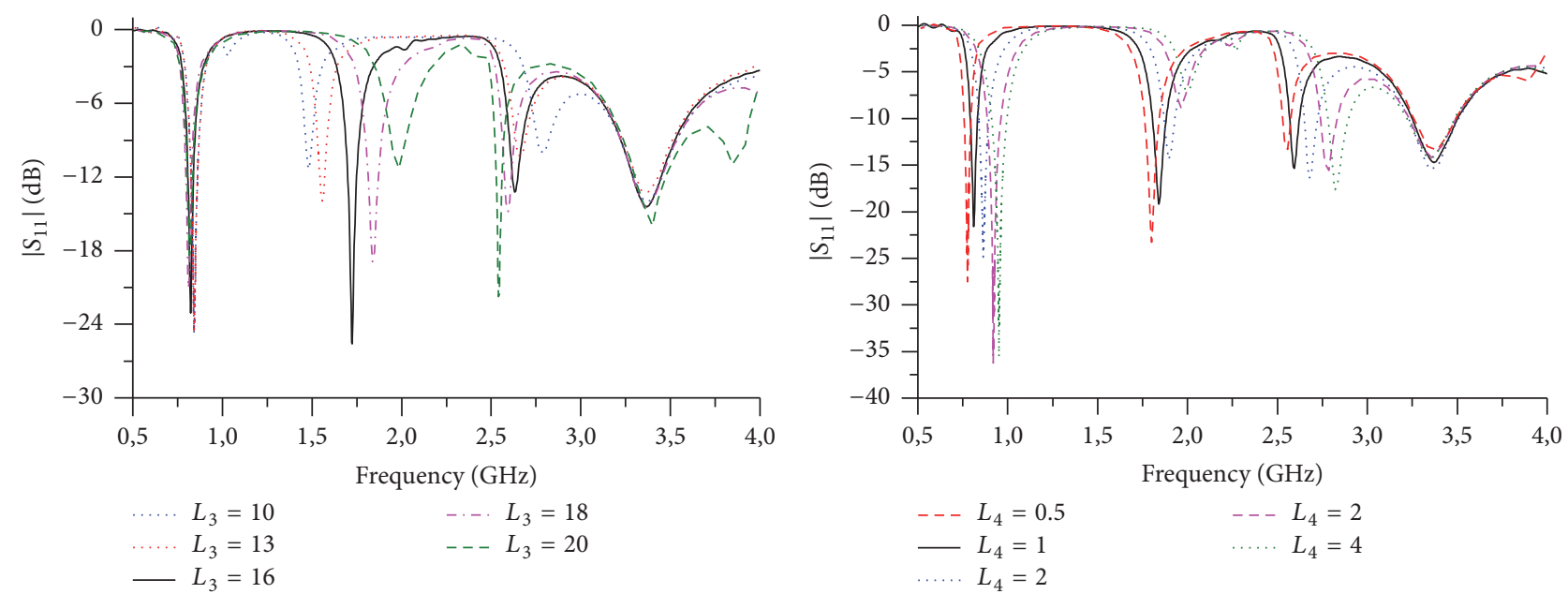

(c)

(d)

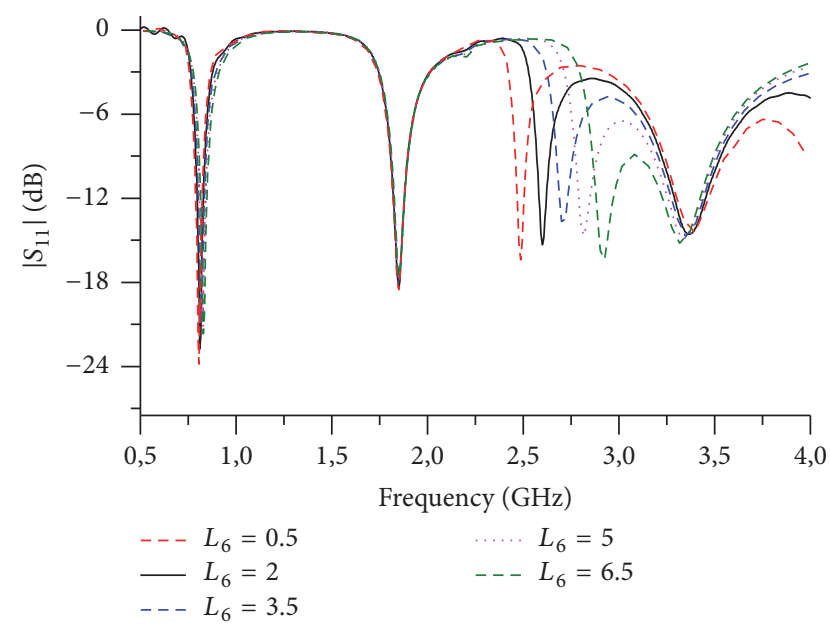

(e)

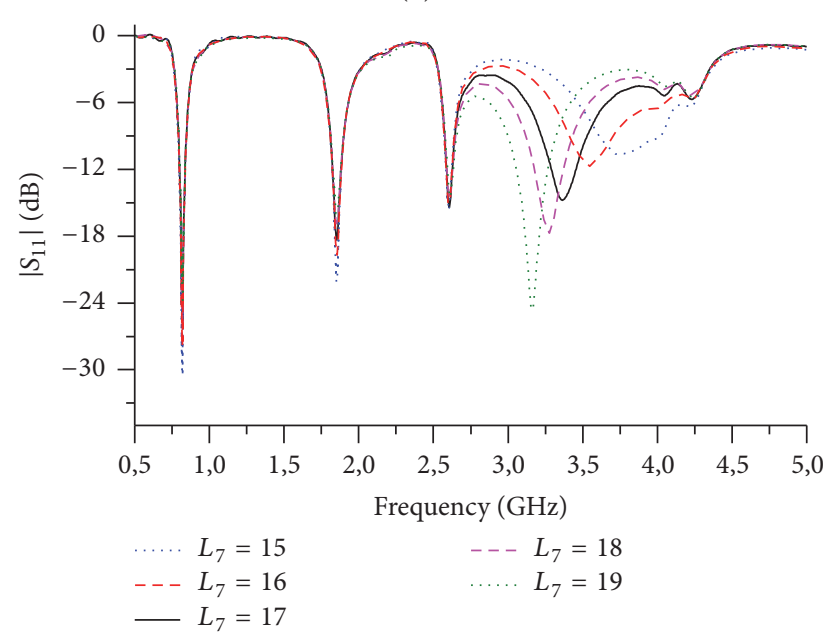

(f)

Figure 4: Simulated reflection coefficient as a function of (a) the parameter $R$, (b) the parameter $L_{1}$, (c) the parameter $L_{3}$, (d) the parameter $L_{4}$, (e) the parameter $L_{6}$, and (f) the parameter $L_{7}$. 


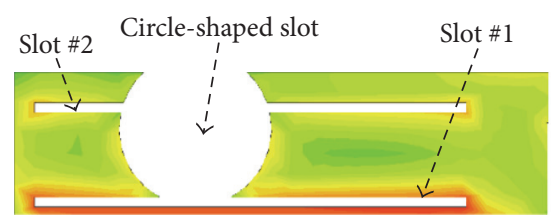

(a)

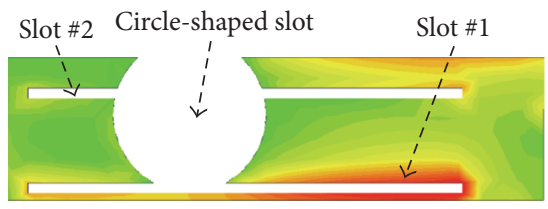

(c)

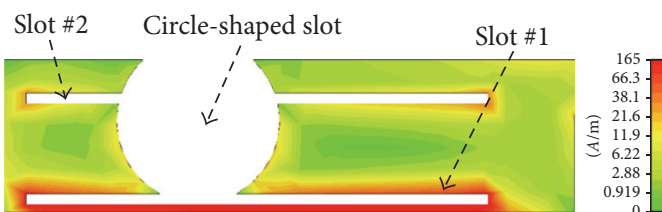

(b)
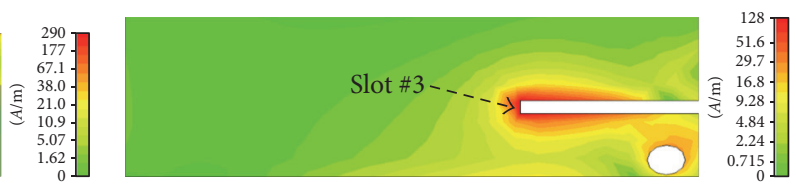

(d)

Figure 5: Surface current distribution of the proposed PIFA: (a) at $790 \mathrm{MHz}$, (b) at $1870 \mathrm{MHz}$, (c) at $2550 \mathrm{MHz}$, and (d) at $3400 \mathrm{MHz}$.

Figure 4(b) shows the effect of the length change of slots \#1 and \#2 $\left(L_{1}\right)$ on the antenna reflection coefficient $\left(L_{1}=36 \mathrm{~mm}\right.$, $39 \mathrm{~mm}, 42 \mathrm{~mm}, 45 \mathrm{~mm}$, and $49 \mathrm{~mm}$ ). From this figure, the resonant frequencies for band \#1, band \#2, and band \#3 shift to lower frequency with increasing $L_{1}$. Therefore, an increase of $L_{1}$ leads to an increase of the effective length of the current around slots \#1 and \#2, which results in a shift towards the low frequencies. Thus, by changing $L_{1}$, the antenna can operate at a different frequency band within $744-885 \mathrm{MHz}$ for band \#1, $1665-2113 \mathrm{MHz}$ for band \#2, and 2385-2915 MHz for band \#3 and without affecting band \#4, as shown in Table 2.

The effects of the position of the circle-shaped slot along the $x$-axis $\left(L_{3}\right)$ on the reflection coefficient are also studied. The simulated reflection coefficient of parameter $L_{3}$ that varies from $10 \mathrm{~mm}$ to $20 \mathrm{~mm}$ is shown in Figure 4 (c) $\left(L_{3}=\right.$ $10 \mathrm{~mm}, 13 \mathrm{~mm}, 16 \mathrm{~mm}, 18 \mathrm{~mm}$, and $20 \mathrm{~mm}$ ). We found from this figure that the resonant frequency of band \#2 increases and the resonant frequency of band $\# 3$ decreases when $L_{3}$ increases. Therefore, the distance between band $\# 2$ and band $\# 3$ increases when $L_{3}$ increases. The parameter $L_{3}$ has a title effect on the resonance frequency of band $\# 1$ and band \#4. Therefore, $L_{3}$ can control at the same time the two bands \#2 and \#3 without affecting the two bands \#1 and \#4. The control ranges for this parameter $L_{3}$ are $1448-2068 \mathrm{MHz}$ (band \#2) and $2500-2900 \mathrm{MHz}$ (band \#3).

The effect of the position of slot \#1 along the $y$-axis $\left(L_{4}\right)$ on the parameter $S_{11}$ of the proposed PIFA is studied. The simulated results in Figure $4(\mathrm{~d})$ are obtained by changing $L_{4}$ from $0.5 \mathrm{~mm}$ to $4 \mathrm{~mm}\left(L_{4}=0.5 \mathrm{~mm}, 1 \mathrm{~mm}, 2 \mathrm{~mm}, 3 \mathrm{~mm}\right.$, and $4 \mathrm{~mm}$ ). We observe, with increasing the parameter $L_{4}$, the resonant frequencies of the first three bands (band \#1, band $\# 2$, and band \#3) are shifted to the high frequencies while the resonant frequency of band \#4 remained unchanged. And, from Table 2, we observe that the control ranges are $745-1025 \mathrm{MHz}, 1735-2026 \mathrm{MHz}$, and $2509-3048 \mathrm{MHz}$ for bands \#1, \#2, and \#3 respectively.

Figure 4(e) shows the simulated $S_{11}$ results with the variation of the position of slot $\# 2$ along $y$-axis $\left(L_{6}\right)$ from $0.5 \mathrm{~mm}$ to $6.5 \mathrm{~mm}$ by a step $1.5 \mathrm{~mm}$. It is observed that, with the increase of $L_{6}$, the resonant frequency of band $\# 3$ increases. These results indicated that $L_{6}$ could be used to tune the resonant frequency of band \#3 without affecting the other bands. Therefore, the control range for this parameter is 2446-3080 MHz (see Table 2).

Figure 4(f) shows parametric study for the length of slot $\# 3\left(L_{7}\right)$ integrated in the ground plane, which generates the operating band \#4 at $3.4 \mathrm{GHz}$ for WIMAX applications. From this figure, it is found that as $L_{7}$ increases, the resonant frequency of band \#4 moves upward. Therefore, the parameter $L_{7}$ mainly controls band \#4 with the range $2880-4253 \mathrm{MHz}$ (as shown in Table 2). And we can see that the highest value of the parameter $\left(L_{7}\right)$ provides better impedance matching in band \#4. The optimum value of parameter $\left(L_{7}\right)$ for band \#4 corresponding to the WIMAX band $(3400 \mathrm{MHz})$ is $L_{7}=$ $17 \mathrm{~mm}$.

2.4. Current Distribution. To understand the behavior of the proposed PIFA the surface current distribution at different frequencies of resonances has been studied. The current distributions at $790 \mathrm{MHz}, 1870 \mathrm{MHz}, 2550 \mathrm{MHz}$, and $3400 \mathrm{MHz}$ are shown in Figures 5(a), 5(b), 5(c), and 5(d), respectively. Figure 5(a) shows the surface current distribution at $790 \mathrm{MHz}$ is excited around slot \#1. In Figure 5(b), the surface current at $1870 \mathrm{MHz}$ is distributed in the right side of the circleshaped slot and has a maximum intensity at the right end of slot \#1. And at $2550 \mathrm{MHz}$, in Figure 5(c), a strong surface current is distributed on the ends of slot \#1 and slot \#2, which indicates that adjusting band \#3 is mainly linked by the variation of the position of slot $\# 1$ and slot $\# 2$ below the $x$-axis. Finally, Figure 5(d) shows the surface current distribution at $3400 \mathrm{MHz}$, and a large current intensity is observed around slot \#3 integrated in the ground plane.

\section{Results and Discussion}

3.1. Reflection Coefficient. The analysis of the proposed PIFA is performed by CST Microwave Studio to optimize the antenna parameters for the desired frequency bands. After that, a prototype of the optimized PIFA is fabricated and validated experimentally. Photographs of the manufactured antenna are shown in Figure 6. The reflection coefficient is 


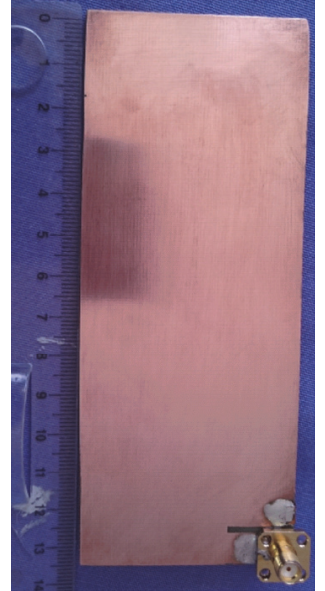

(a)

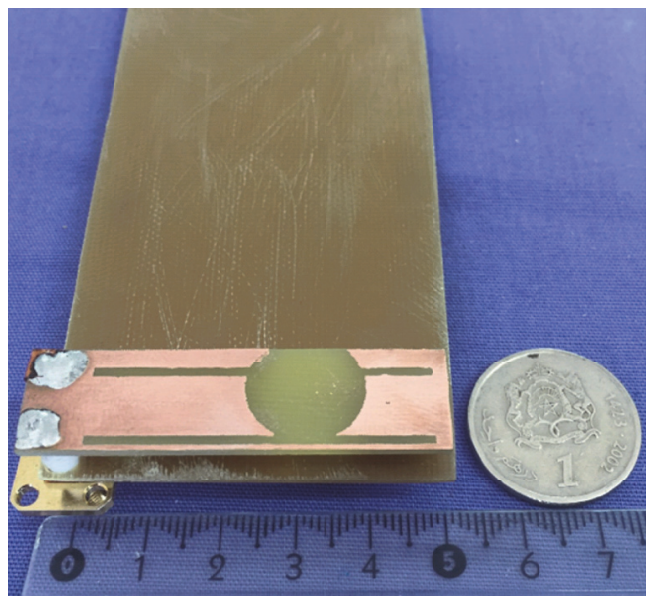

(b)

FIGURE 6: The manufactured PIFA: (a) ground plane and (b) radiating patch.

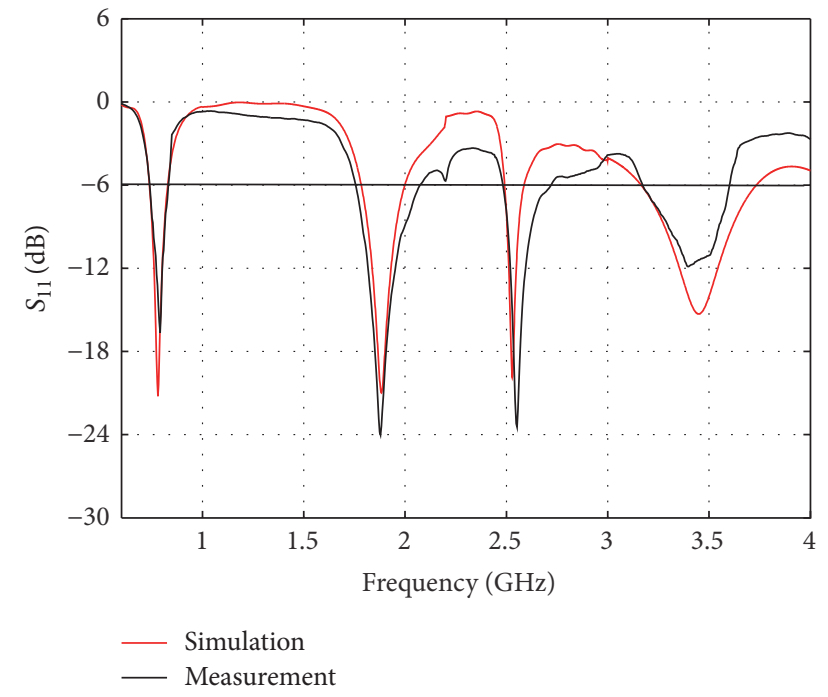

FIGURE 7: Simulated and measured $S_{11}$ of the proposed PIFA.

measured using the Vector Network Analyzer and compared with the simulated reflection coefficient in Figure 7. From this figure, we observed a good agreement between the simulated and measured results. A shift in bands \#3 and \#4 is mainly due to the measurement environment and manufacturing errors.

Four operating bands of the proposed PIFA are obtained: the first band $\left(S_{11}<-6 \mathrm{~dB}\right)$ from $737 \mathrm{MHz}$ to $831 \mathrm{MHz}$ with a width of $93 \mathrm{MHz}$, the second band $\left(S_{11}<-10 \mathrm{~dB}\right)$ from $1794 \mathrm{MHz}$ to $1977 \mathrm{MHz}$ with a width of $183 \mathrm{MHz}$, the third band $\left(S_{11}<-10 \mathrm{~dB}\right)$ from $2507 \mathrm{MHz}$ to $2615 \mathrm{MHz}$ with a width of $108 \mathrm{MHz}$, and the fourth band $\left(S_{11}<-10 \mathrm{~dB}\right)$ from $3341 \mathrm{MHz}$ to $3545 \mathrm{MHz}$ with a width of $204 \mathrm{MHz}$. The four bands obtained cover the LTE700, LTE800, DCS1800, PCS1900, LTE1800, LTE1900, LTE2500, and WIMAX3400 bands.
3.2. Radiation Pattern. The radiation patterns in $2 \mathrm{D}$ of the proposed PIFA at $790 \mathrm{MHz}, 1870 \mathrm{MHz}, 2550 \mathrm{MHz}$, and $3400 \mathrm{MHz}$ are shown in Figures 8(a), 8(b), 8(c), and 8(d), respectively. From Figure $8(\mathrm{a})$, it is observed that the radiation patterns at $790 \mathrm{MHz}$ are similar to a dipole's, due to the form of the antenna-PCB combination. An omnidirectional radiation pattern is observed at $1870 \mathrm{MHz}$ and $2550 \mathrm{MHz}$, in Figures 8(b) and 8(c). For Figure 8(d), some variations in the radiation patterns can be seen at $3400 \mathrm{MHz}$, which is due to the integration of slot \#3 in the ground plane.

3.3. Gain and Radiation Efficiency. Figure 9 shows the variation of the gain and radiation efficiency of the proposed PIFA. The gain varied from 1.67 to $2.15 \mathrm{dBi}$ for the $790 \mathrm{MHz}$ band, from 2.56 to $3.99 \mathrm{dBi}$ for the $1870 \mathrm{MHz}$ band, from 2.28 to $5.38 \mathrm{dBi}$ for the $2550 \mathrm{MHz}$ band, and from 5.81 to $6.62 \mathrm{dBi}$ for the $3400 \mathrm{MHz}$ band. And the radiation efficiency is around 60 to $63.29 \%$ for the first band, 64.75 to $72.93 \%$ for the second band, 39.53 to $71.59 \%$ for the third band, and 74.28 to $80.25 \%$ for the fourth band.

\section{The Proposed PIFA in Handset}

To examine a real model, the proposed PIFA is integrated into a smartphone case which has many components such as liquid crystal display (LCD) $\left(50 \times 100 \times 2 \mathrm{~mm}^{3}\right)$, battery $(50 \times$ $\left.90 \times 3 \mathrm{~mm}^{3}\right)$, microphone $\left(5 \times 4 \times 3 \mathrm{~mm}^{3}\right)$, digital camera (diameter $=10 \mathrm{~mm}$ and thickness $=7 \mathrm{~mm})$, speaker $(7 \times 6 \times$ $3 \mathrm{~mm}^{3}$ ), and buttons [25]. In addition, the effect of the mobile phone environment on the reflection coefficient of the proposed PIFA is also studied. The geometric model of mobile phone with its components is shown in Figure 10. The battery is placed in the backside of the phone (the same side or the PIFA is fabricated), while the LCD is placed in the front side (the same side of the ground plane). The distance between the battery and PIFA is $16 \mathrm{~mm}$; it is chosen so as 


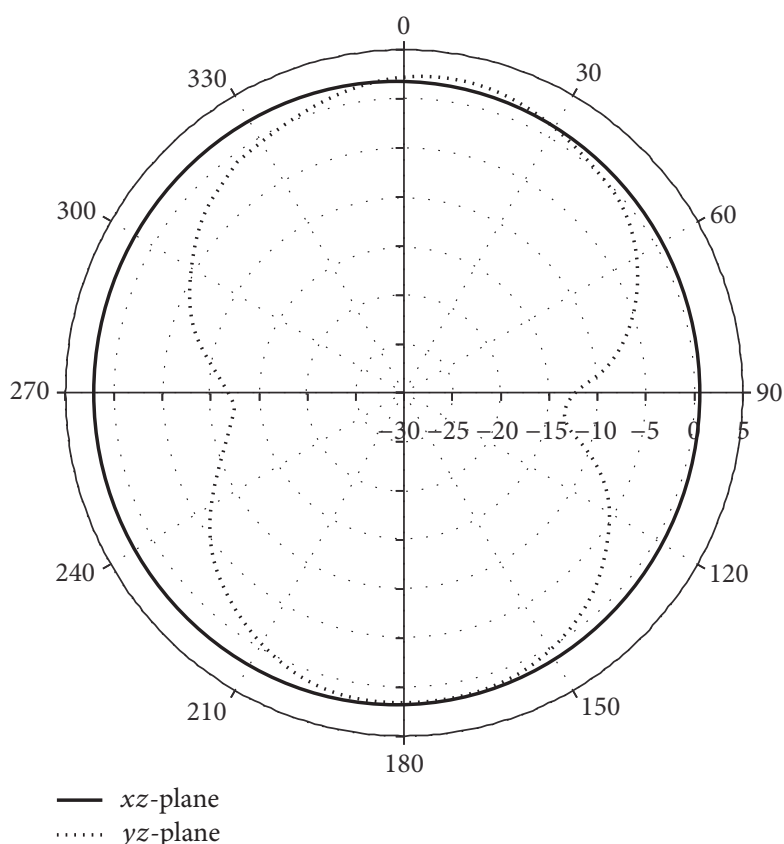

(a)

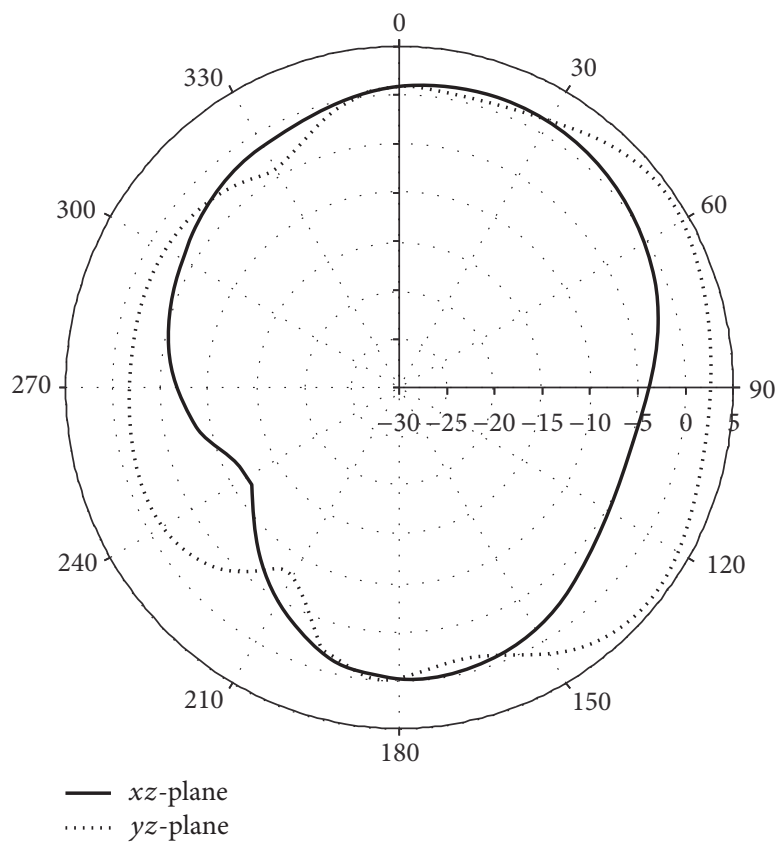

(c)

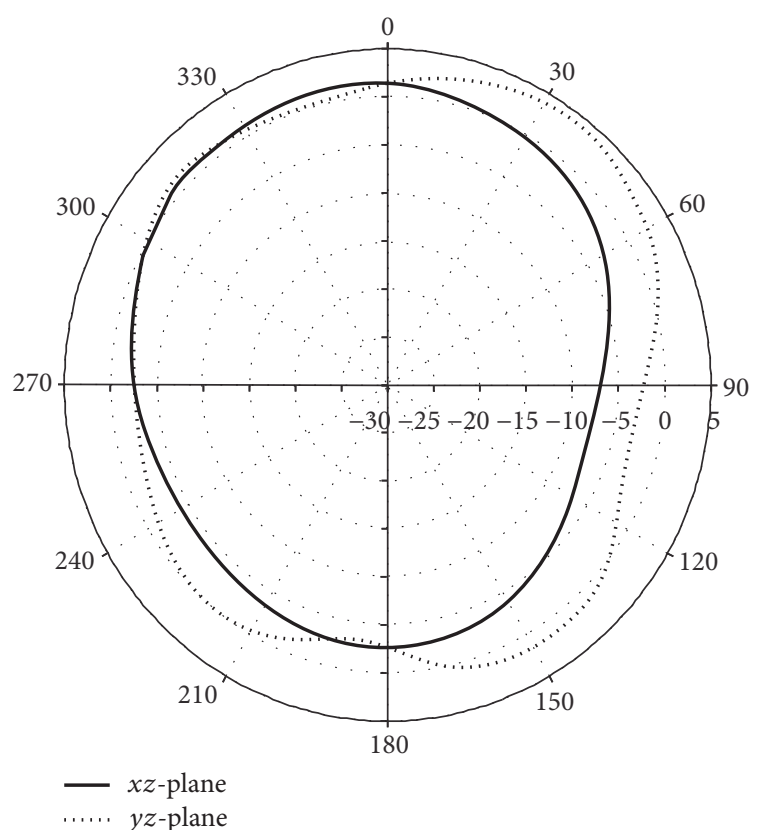

(b)

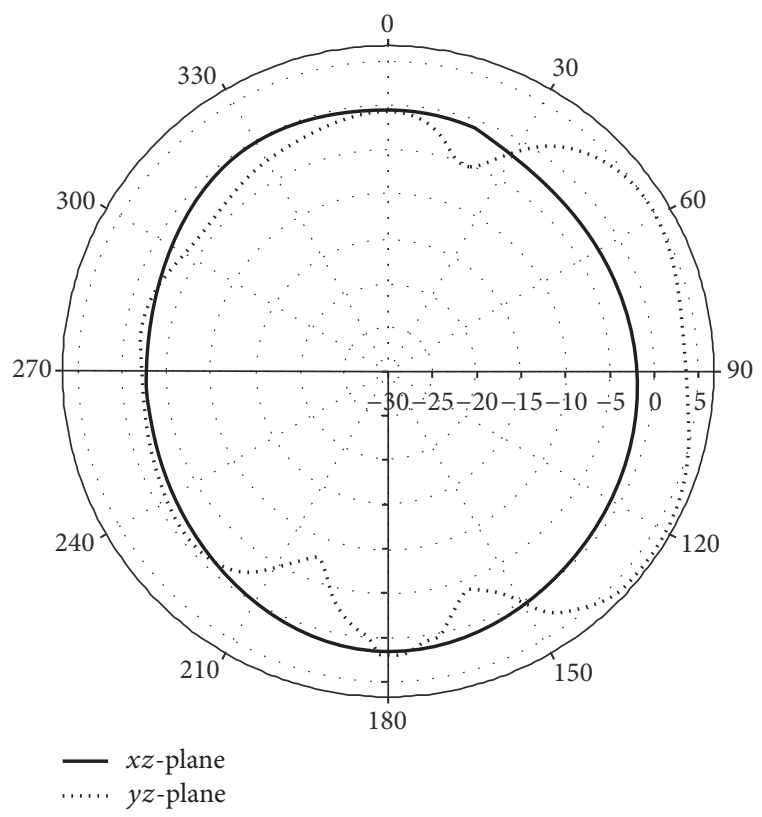

(d)

Figure 8: Radiation patterns of the proposed PIFA: (a) at $790 \mathrm{MHz}$, (b) at $1870 \mathrm{MHz}$, (c) at $2550 \mathrm{MHz}$, and (d) at $3400 \mathrm{MHz}$.

not to affect the antenna performance [26]. The LCD and the battery are in parallel with a distance of $2 \mathrm{~mm}$, and they are connected to PCB via connectors as shown in Figure 10(c). The connectors are located in the end of the substrate away from the PIFA. Digital camera is positioned in the same position of the circle-shaped slot (Figure 10(a)). The speaker is placed in the front side in parallel with digital camera (Figure 10(b)). The microphone is positioned in the lower part of PCB (Figure 10(a)). Small metal parts such as buttons and connectors are set away from PIFA. All these components are considered as perfect electrical conductor for simulation [27]. All these components of mobile telephone and the antenna are covered with a plastic housing (1 $\mathrm{mm}$ thickness).

Figure 11 shows the variation of the reflection coefficient in free space and in the mobile phone environment. From this figure, we observe a significant effect of the mobile environment on the reflection coefficient of the proposed PIFA. For band \#1 and band \#3, the central frequencies are 


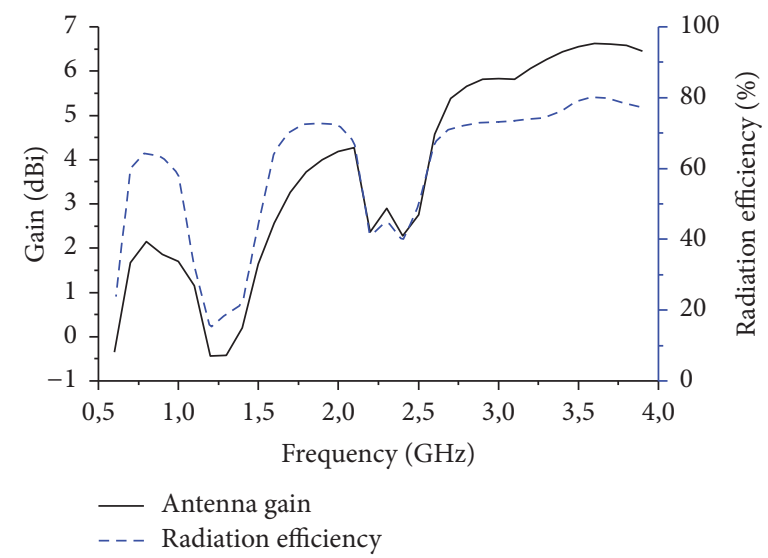

FIGURE 9: Gain and radiation efficiency of the proposed PIFA.

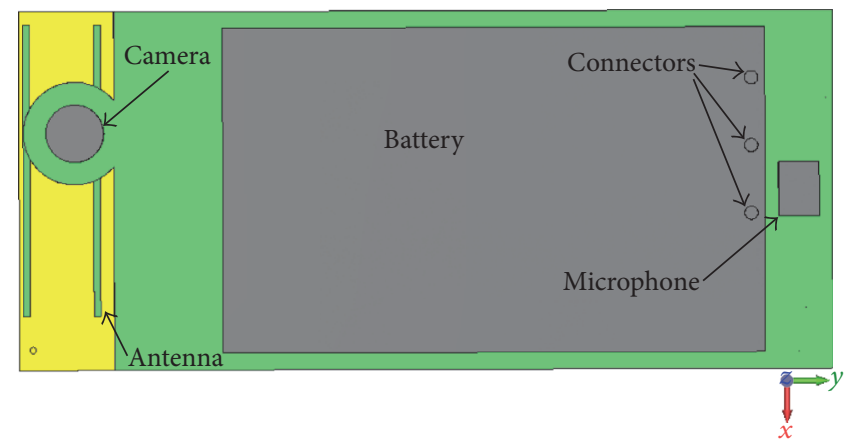

(a)

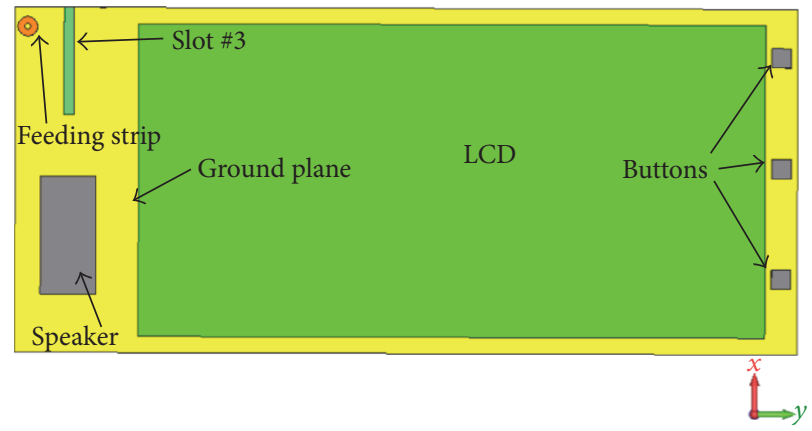

(b)

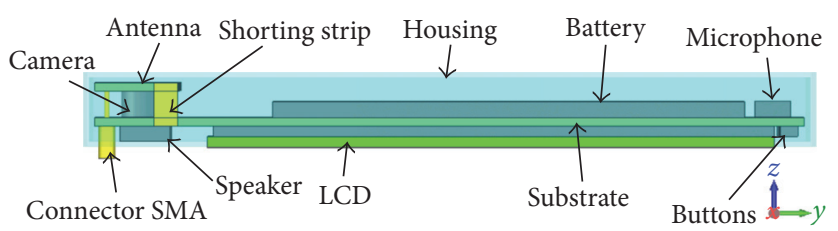

(c)

FIGURE 10: Structure of the mobile handset: (a) front view, (b) back view, and (c) side view.

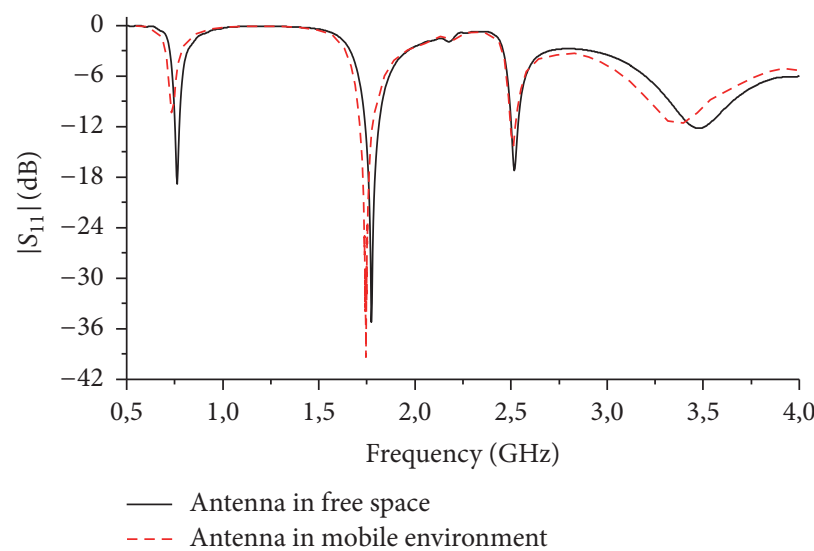

FIGURE 11: The simulated reflection coefficient of the proposed PIFA in handset. 


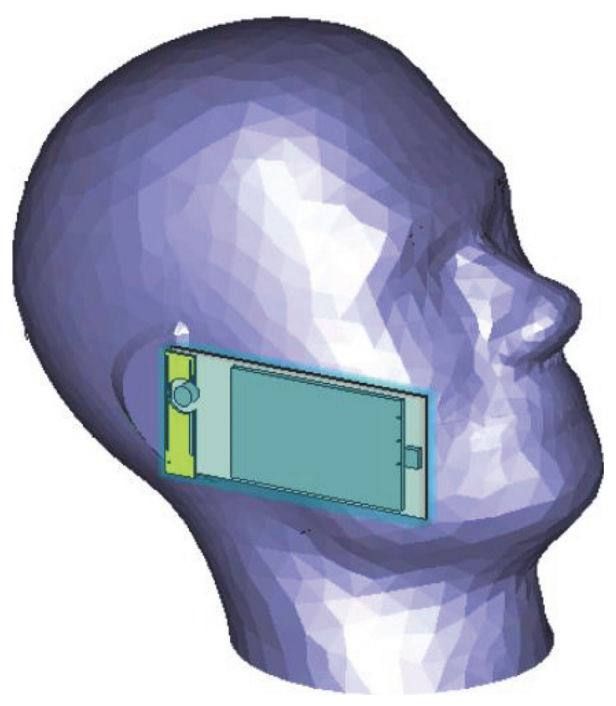

(a)

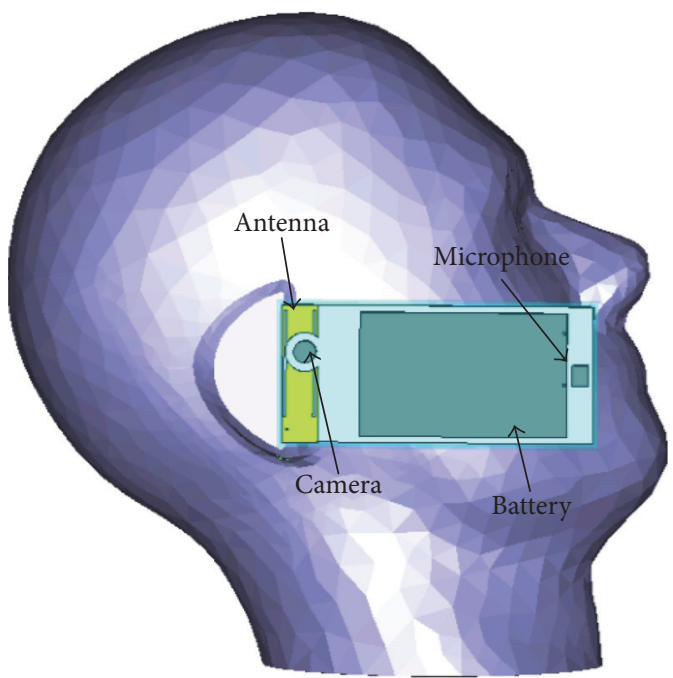

(b)

FIGURE 12: SAR simulation model and the mobile phone position.

shifted to lower frequencies with a decrease in the impedance matching. For band \#2 and band \#4, it is interesting to note that the resonance frequencies are shifted to lower frequencies with improved antenna matching and bandwidth. This is mainly due to the position of the camera and speaker, which are close to PIFA, and the large size of the LCD.

\section{Specific Absorption Rate (SAR)}

The specific absorption rate (SAR) is a very important parameter for the antennas design for mobile phones. SAR assesses the amount of energy absorbed by biological tissue mass unit while using the mobile phone [27]. This parameter can be calculated by the following equation:

$$
\operatorname{SAR}=\frac{\sigma|E|^{2}}{2 \rho},
$$

where $\rho\left(\mathrm{kg} / \mathrm{m}^{3}\right)$ and $\sigma(\mathrm{S} / \mathrm{m})$ are the body tissue density and conductivity, respectively. $E(\mathrm{~V} / \mathrm{m})$ is the root-mean-square (rms) value of the electric field strength in the tissue. All the studies proposed in this section are based on simulations performed by CST Microwave Studio. For analyzing the EM absorbing characteristics of the proposed PIFA, we used a numerical Specific Anthropomorphic Mannequin (SAM) head model available in CST Microwave Studio, which consists of two layers of fluid and shell (Figure 12). To get results close to reality, the parameters used for the human head model are SAM liquid (relative permittivity $\varepsilon_{r}=42$, conductivity $\sigma=0.99 \mathrm{~S} / \mathrm{m}$, and density $\rho=1000 \mathrm{Kg} / \mathrm{m}^{3}$ ) and SAM shell (relative permittivity $\varepsilon_{r}=5$, conductivity $\sigma=$ $0.0125173 \mathrm{~S} / \mathrm{m}$, and density $\rho=0 \mathrm{Kg} / \mathrm{m}^{3}$ ). However, a complete phone model that consists of housing, battery, microphone, speaker, buttons, camera, and LCD has been used. The antenna is positioned at the upper part of the mobile phone close to the ear of phantom. The distance between the antenna and the human head is chosen to be reasonably $2 \mathrm{~mm}$ to test the SAR.

SAR distribution results obtained for the two European (average 1-g) and American (average 10-g) standards at $790 \mathrm{MHz}, 1870 \mathrm{MHz}, 2550 \mathrm{MHz}$, and $3400 \mathrm{MHz}$ are shown in Figures 13, 14, 15, and 16, respectively. From these figures, we see that the SAR values for the proposed PIFA are below the limit specified by the two standards. The SAR results obtained indicate that the proposed PIFA is a promising candidate for modern mobile phones.

The variations of SAR with the distance between antenna and human head are also studied. Figures 17(a), 17(b), 17(c), and $17(\mathrm{~d})$ show the variations of SAR with the distance between the antenna and the human head (from $0 \mathrm{~mm}$ to $16 \mathrm{~mm}$ with a step of $2 \mathrm{~mm}$ ) at $790 \mathrm{MHz}, 1870 \mathrm{MHz}$, $2550 \mathrm{MHz}$, and $3400 \mathrm{MHz}$, respectively. From these figures, it is observed that the increase in the distance between the proposed PIFA and the human head exhibits a significant SAR reduction at each resonant frequency. That is, the increase in distance between the antenna and human head reduces the electric and magnetic field during the use of mobile phone, and hence SAR value decreases [28].

\section{Conclusion}

A new compact quad-band PIFA for mobile phone is proposed. The proposed PIFA is designed to operate in LTE700, LTE800, DCS1800, PCS1900, LTE1800, LTE1900, LTE2500, and WIMAX3400 bands. Since the proposed PIFA is of small size and simple geometry, it is easy to manufacture and integrate in the case of mobile phones. Three slots were added to the radiating patch and the ground plane to generate four operating bands, which can be controlled independently by adjusting the antenna parameters. The results of simulated and measured reflection coefficient for the proposed PIFA 


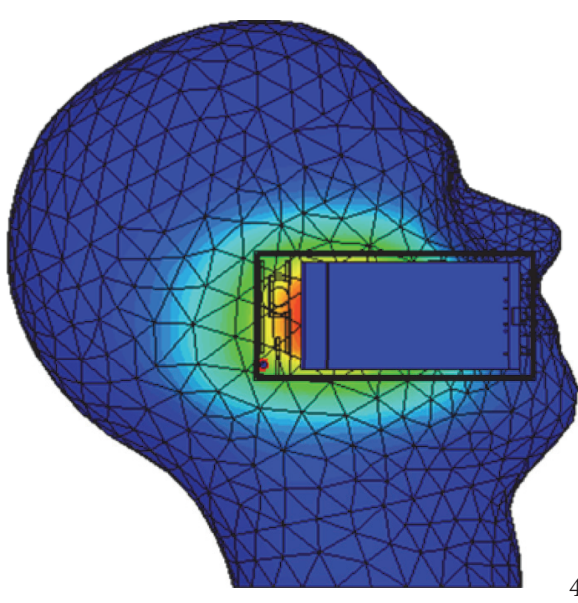

(a)

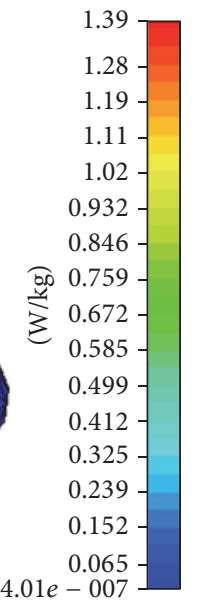

FIGURE 13: SAR distribution at $790 \mathrm{MHz}$ : (a) average 1-g and (b) average 10-g.

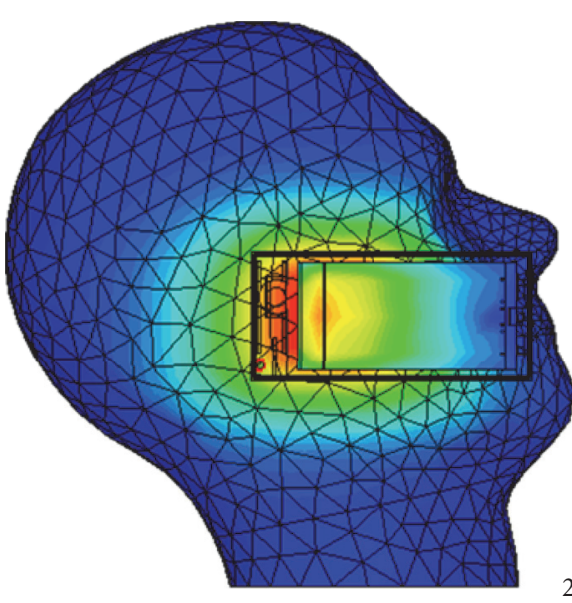

(b)

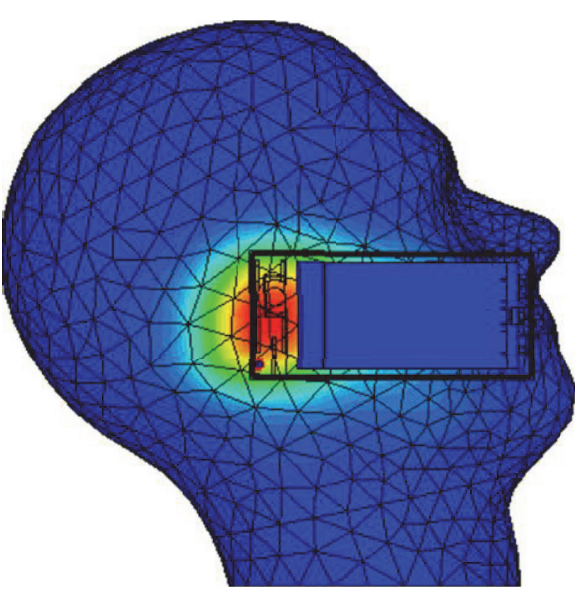

(a)

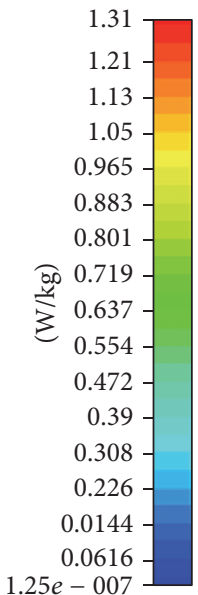

$1.25 e-007$

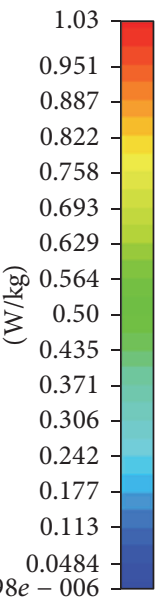

$.98 e-006$

FIGURE 14: SAR distribution at $1870 \mathrm{MHz}$ (a) average 1-g and (b) average 10-g

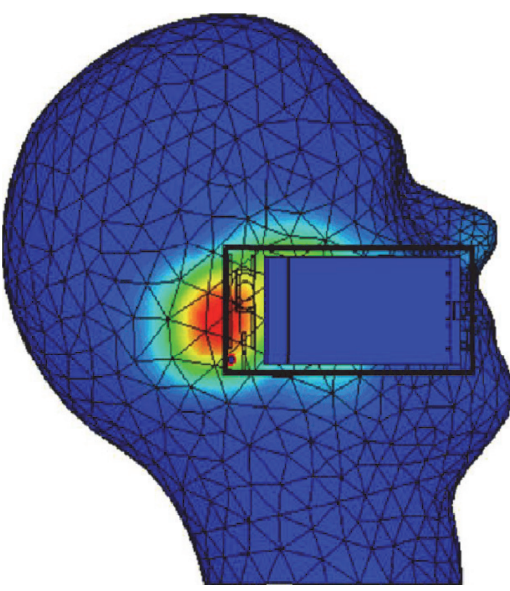

(a)

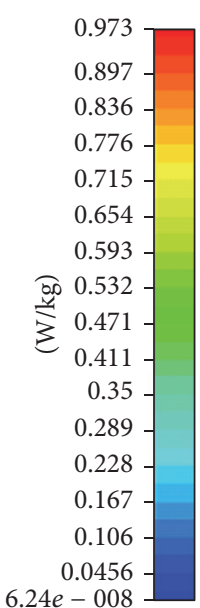

$6.24 e-008$

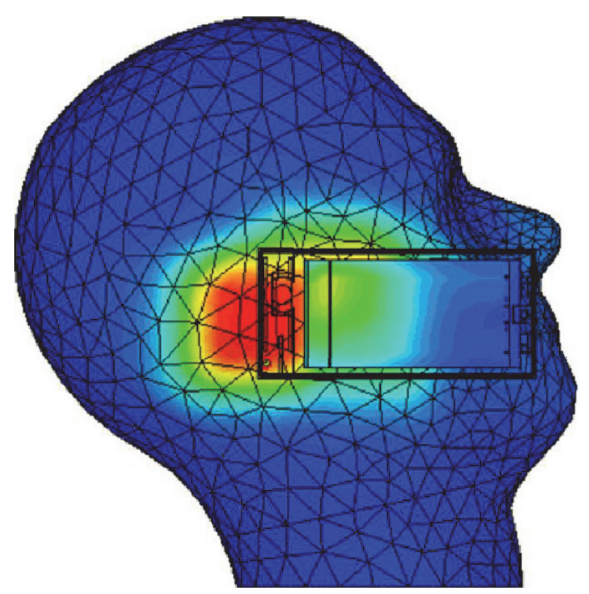

(b)

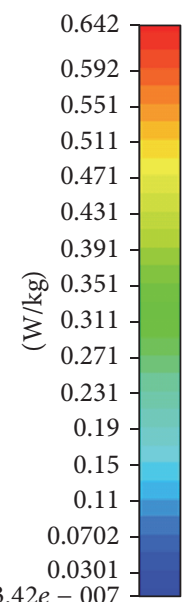

$3.42 e-007$

FIGURE 15: SAR distribution at $2550 \mathrm{MHz}$ (a) average 1-g and (b) average 10-g. 


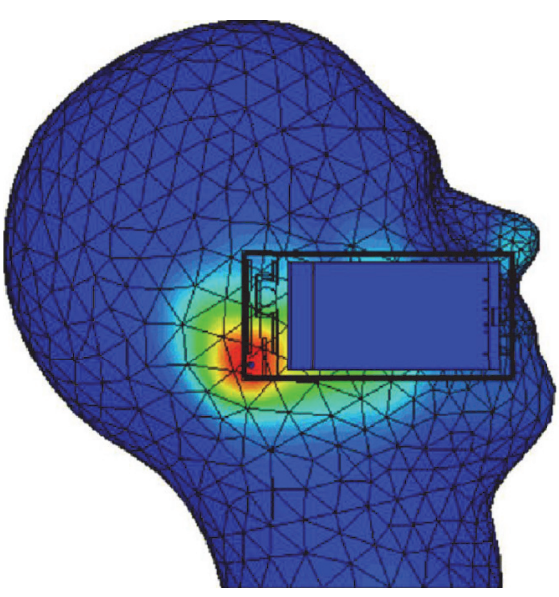

(a)

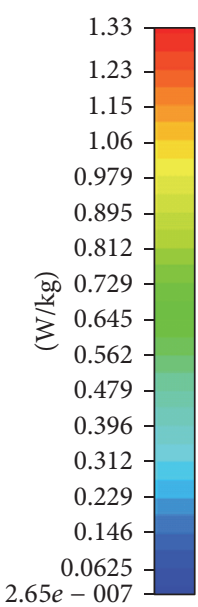

FIGURE 16: SAR distribution at $3400 \mathrm{MHz}$ (a) average 1-g and (b) average 10-g.

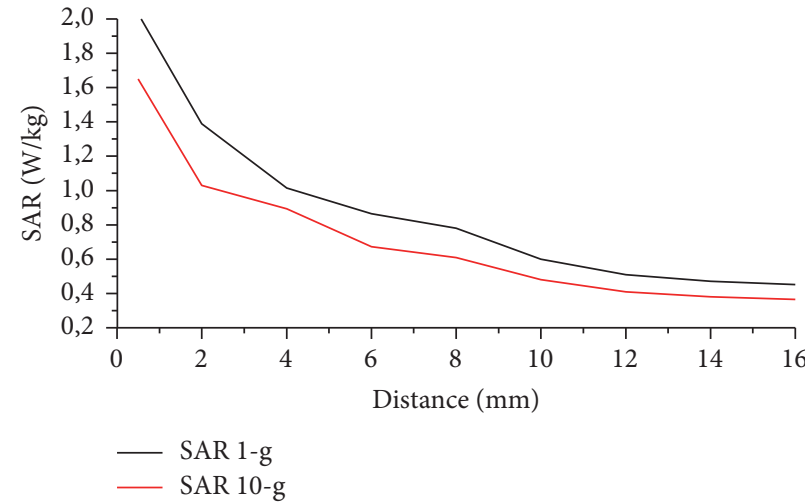

(a)

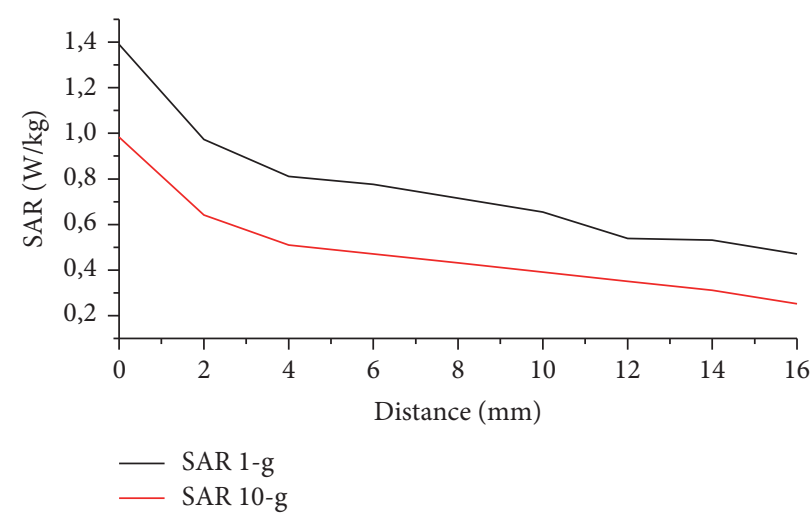

(c)

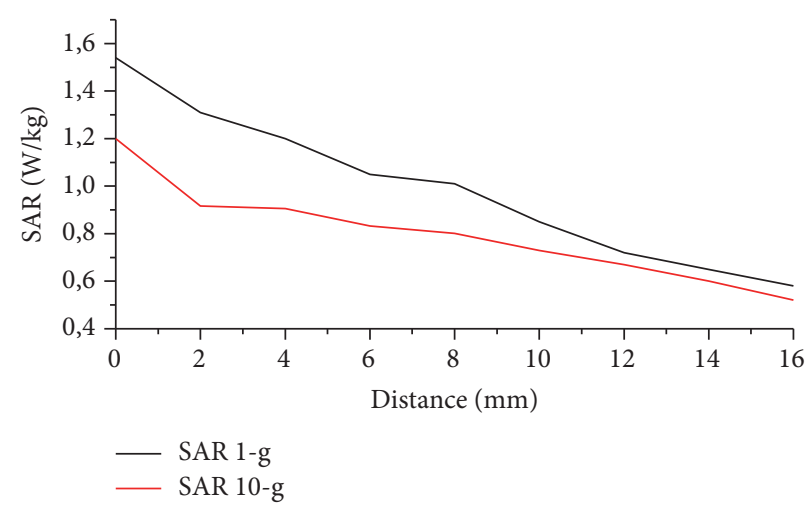

(b)

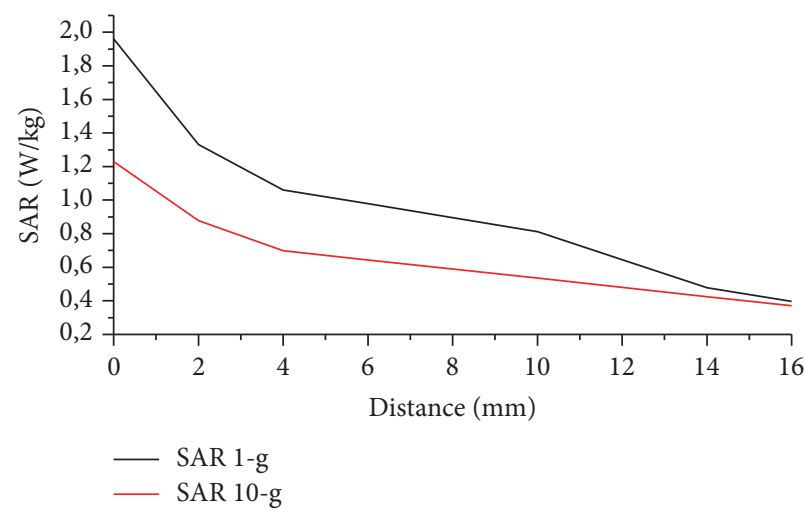

(d)

FIGURE 17: SAR variation in terms of the distance between the PIFA and the head: (a) at $790 \mathrm{MHz},(\mathrm{b})$ at $1870 \mathrm{MHz},(\mathrm{c})$ at $2550 \mathrm{MHz}$, and (d) at $3400 \mathrm{MHz}$.

show good agreement. Good radiation characteristics in each operating band are obtained. The antenna gain is about $2.15 \mathrm{~dB}$ at $790 \mathrm{MHz}, 3.99 \mathrm{~dB}$ at $1870 \mathrm{MHz}, 4.57 \mathrm{~dB}$ at $2600 \mathrm{MHz}$, and $6.43 \mathrm{~dB}$ at $3400 \mathrm{MHz}$. The effect of other mobile phone components on the reflection coefficient is considered to be less important. The SAR test on the human head phantom shows that the SAR values are acceptable for mobile phone applications. Therefore, the optimized PIFA is quite competitive for the mobile handset applications to 4thgeneration wireless communication. 


\section{Conflicts of Interest}

The authors declare that there are no conflicts of interest regarding the publication of this paper.

\section{Acknowledgments}

The authors would like to express their sincere gratitude to the support by Naima A. Touhami of Electronics, Instrumentation and Microwave Laboratory, Faculty of Sciences, Abdelmalek Essaadi University, Tetouan, Morocco.

\section{References}

[1] J. Ilvonen, R. Valkonen, J. Holopainen, and V. Viikari, "Design strategy for $4 \mathrm{G}$ handset antennas and a multiband hybrid antenna," IEEE Transactions on Antennas and Propagation, vol. 62, no. 4, pp. 1918-1927, 2014.

[2] C. Rowell and E. Y. Lam, "Mobile-phone antenna design," IEEE Antennas and Propagation Magazine, vol. 54, no. 4, pp. 14-34, 2012.

[3] G. Wen, Q. Rao, S. M. Ali, and D. Wang, "Handset antenna design: practice and theory," Progress in Electromagnetics Research, vol. 80, pp. 123-160, 2008.

[4] Y. Xu and H.-M. Zhou, "Small-size narrow-frame PIFA for LTE/WWAN/GNSS handset application," Microwave and Optical Technology Letters, vol. 58, no. 7, pp. 1689-1693, 2016.

[5] P. Li, J. Pan, D. Yang, and P. Nie, "A novel dual-shorting point PIFA (GSM850 to IMT-A) for mobile handsets," International Journal of Antennas and Propagation, vol. 2013, Article ID 436808, 7 pages, 2013.

[6] Y.-C. Yu and J.-H. Tarng, "A novel modified multiband planar inverted-F antenna," IEEE Antennas and Wireless Propagation Letters, vol. 8, pp. 189-192, 2009.

[7] L. Rudant, C. Delaveaud, and P. Ciais, "Compact multiantenna," International Journal of Antennas and Propagation, vol. 2012, Article ID 748070, 6 pages, 2012.

[8] P. Ciais, R. Staraj, G. Kossiavas, and C. Luxey, "Design of an internal quad-band antenna for mobile phones," IEEE Microwave and Wireless Components Letters, vol. 14, no. 4, pp. 148150, 2004.

[9] J. Anguera, I. Sanz, J. Mumbrú, and C. Puente, "Multiband handset antenna with a parallel excitation of PIFA and slot radiators," IEEE Transactions on Antennas and Propagation, vol. 58, no. 2, pp. 348-356, 2010.

[10] R. Gómez-Villanueva, R.-Y. Linares, J. A. Tirado-Méndez, and H. Jardón-Aguilar, "Ultra-wideband planar inverted-F antenna (PIFA) for mobile phone frequencies and ultra-wideband applications," Progress In Electromagnetics Research C, vol. 43, pp. 109-120, 2013.

[11] C. H. See, R. A. Abd-Alhameed, D. Zhou, and P. S. Excell, "A planar inverted-f-l antenna (pifla) with a rectangular feeding plate for lower-band uwb applications," IEEE Antennas and Wireless Propagation Letters, vol. 9, pp. 149-151, 2010.

[12] M. El Halaoui, A. Kaabal, H. Asselman, S. Ahyoud, and A. Asselman, "Dual-band planar inverted-F antenna with enhanced bandwidth by adding a T-shaped slot and a two elements for mobile phone applications," Progress In Electromagnetics Research C, vol. 59, pp. 149-158, 2015.

[13] M. F. Abedin and M. Ali, "Modifying the ground plane and its effect on planar inverted-F antennas (PIFAs) for mobile phone handsets," IEEE Antennas and Wireless Propagation Letters, vol. 2, no. 1, pp. 226-229, 2003.
[14] H. Elsadek and D. M. Nashaat, "Multiband and UWB V-shaped antenna configuration for wireless communications applications," IEEE Antennas and Wireless Propagation Letters, vol. 7, pp. 89-91, 2008

[15] H. T. Chattha, Y. Huang, and Y. Lu, "PIFA bandwidth enhancement by changing the widths of feed and shorting plates," IEEE Antennas and Wireless Propagation Letters, vol. 8, pp. 637-640, 2009.

[16] S. Ibnyaich, A. Ghammaz, and M. M. Hassani, "Planar inverted$\mathrm{F}$ antenna with J-shaped slot and parasitic element for ultrawide band application," International Journal of Microwave and Wireless Technologies, vol. 4, no. 6, pp. 613-621, 2012.

[17] R. Gómez-Villanueva, R.-Y. Linares, J. A. Tirado-Méndez, and H. Jardón-Aguilar, "Ultra-wideband planar inverted-F antenna (PIFA) for mobile phone frequencies and ultra-wideband applications," Progress In Electromagnetics Research C, vol. 43, pp. 109-120, 2013.

[18] M. Y. Man, R. Yang, Z. Y. Lei, Y. J. Xie, and J. Fan, "Ultrawideband planar inverted-F antennas with cut-etched ground plane," Electronics Letters, vol. 48, no. 14, pp. 817-818, 2012.

[19] R. Gomez-Villanueva, R. Linares-Y-Miranda, J. A. TiradoMendez, and H. Jardon-Aguilar, "Very broadband PIFA antenna for mobile communications and ultrawideband services," Microwave and Optical Technology Letters, vol. 56, no. 2, pp. 313-316, 2014.

[20] H. F. AbuTarboush, R. Nilavalan, T. Peter, and S. W. Cheung, "Multiband inverted-F antenna with independent bands for small and slim cellular mobile handsets," IEEE Transactions on Antennas and Propagation, vol. 59, no. 7, pp. 2636-2645, 2011.

[21] D.-Y. Kim, J. W. Lee, C. S. Cho, and T. K. Lee, "Design of a compact tri-band PIFA based on independent control of the resonant frequencies," IEEE Transactions on Antennas and Propagation, vol. 56, no. 5, pp. 1428-1436, 2008.

[22] A. M. Soliman, D. M. N. Elsheakh, and E. A. Abdallah, "Low specific absorption rate hexa-band coplanar waveguidefed planar inverted-F antenna with independent resonant frequency control for wireless communication applications," IET Microwaves, Antennas \& Propagation, vol. 8, no. 4, pp. 207-216, 2014.

[23] R. A. Bhatti, Y.-T. Im, and S.-O. Park, "Compact PIFA for mobile terminals supporting multiple cellular and non-cellular standards," IEEE Transactions on Antennas and Propagation, vol. 57, no. 9, pp. 2534-2540, 2009.

[24] K.-L. Wong, Y.-C. Lin, and B. Chen, "Internal patch antenna with a thin air-layer substrate for GSM/DCS operation in a PDA phone," IEEE Transactions on Antennas and Propagation, vol. 55, no. 4, pp. 1165-1172, 2007.

[25] P. K. Bharti, G. K. Pandey, H. S. Singh, and M. K. Meshram, "A compact multiband planar monopole antenna for slim mobile handset applications," Progress In Electromagnetics Research B, vol. 61, no. 1, pp. 31-42, 2014.

[26] K.-L. Wong, H.-J. Chang, F.-H. Chu, W.-Y. Li, and C.-Y. Wu, "WWAN/LTE handset antenna with shaped circuit board, battery, and metal midplate," Microwave and Optical Technology Letters, vol. 55, no. 10, pp. 2254-2261, 2013.

[27] K. S. Sultan, H. H. Abdullah, and E. A. Abdallah, "Low SAR, simple printed compact multiband antenna for mobile and wireless communication applications," International Journal of Antennas and Propagation, vol. 2014, Article ID 946781, 8 pages, 2014.

[28] M. I. Hossain, M. R. I. Faruque, and M. T. Islam, "Analysis on the effect of the distances and inclination angles between human head and mobile phone on SAR," Progress in Biophysics and Molecular Biology, vol. 119, no. 2, pp. 103-110, 2015. 


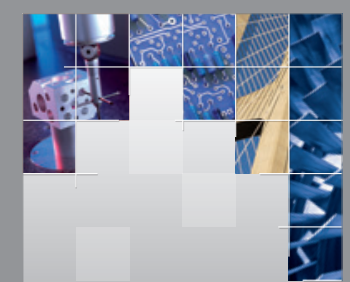

\section{Enfincering}
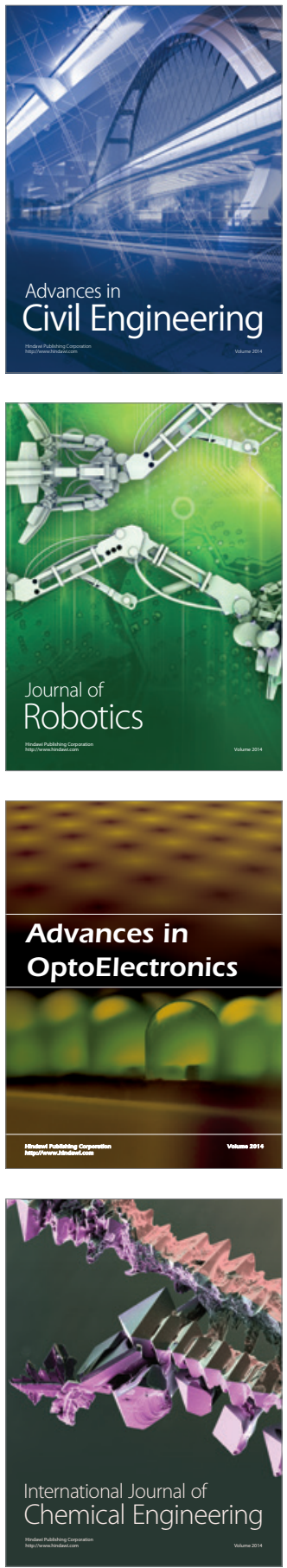

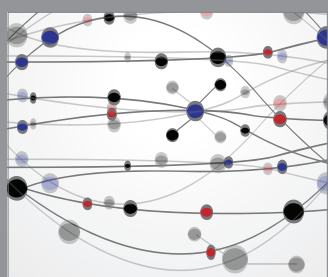

The Scientific World Journal

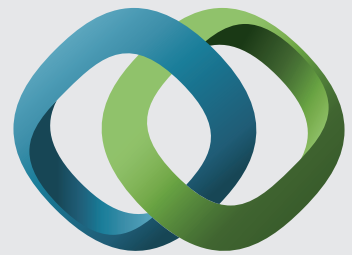

\section{Hindawi}

Submit your manuscripts at

https://www.hindawi.com
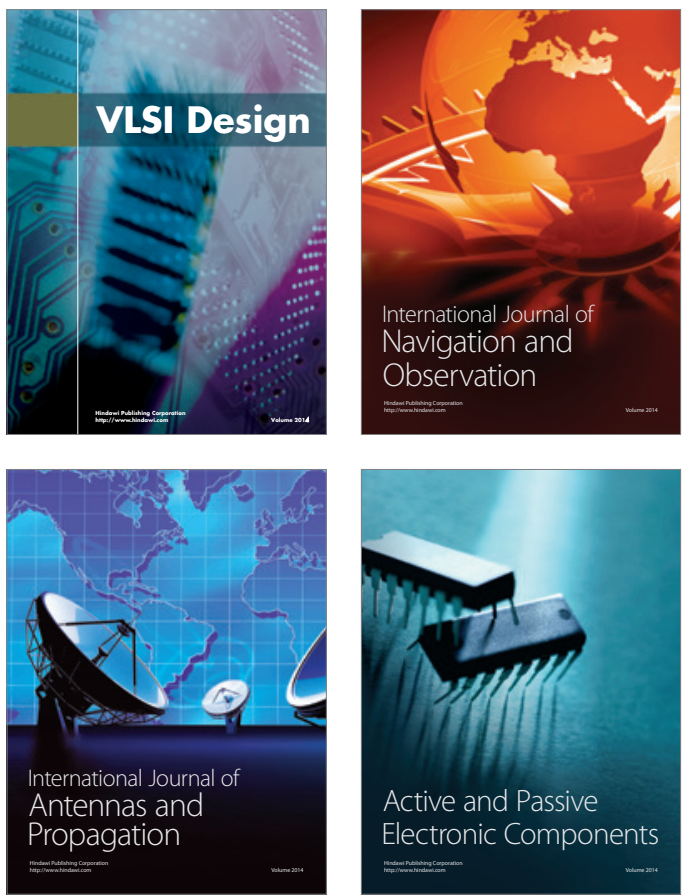
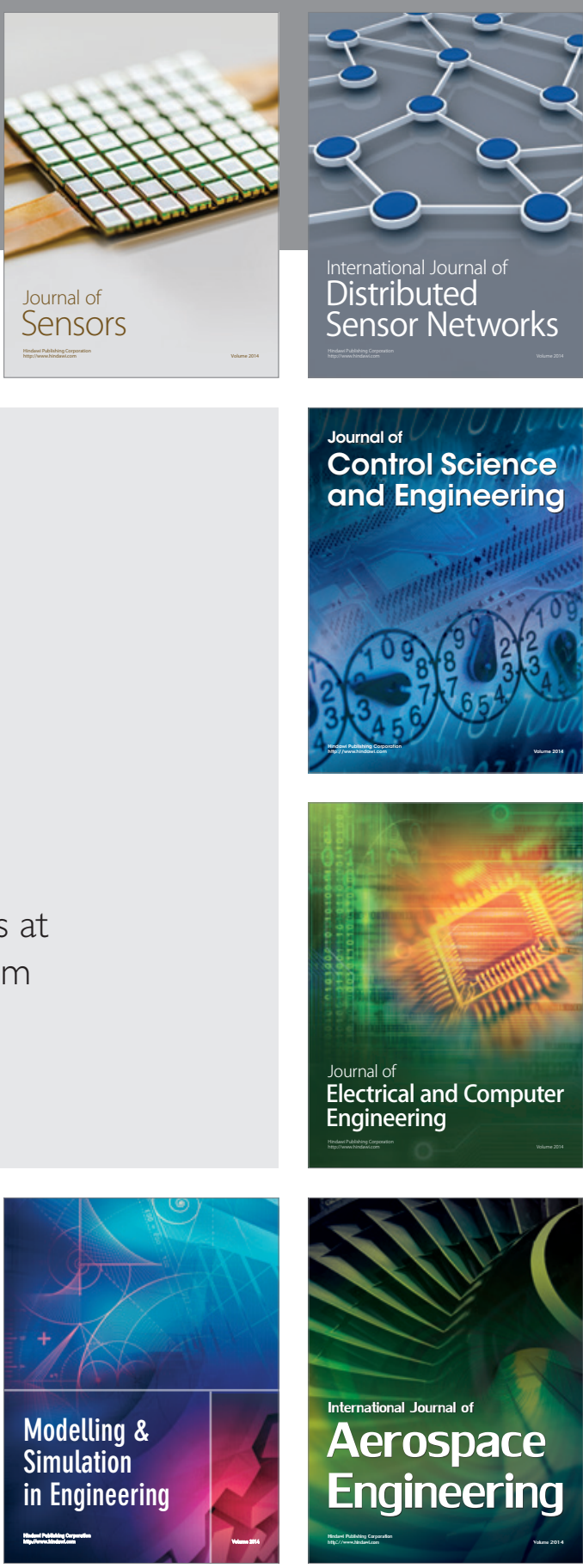

International Journal of

Distributed

Sensor Networks

$-$

Joumal of

Control Science

and Engineering
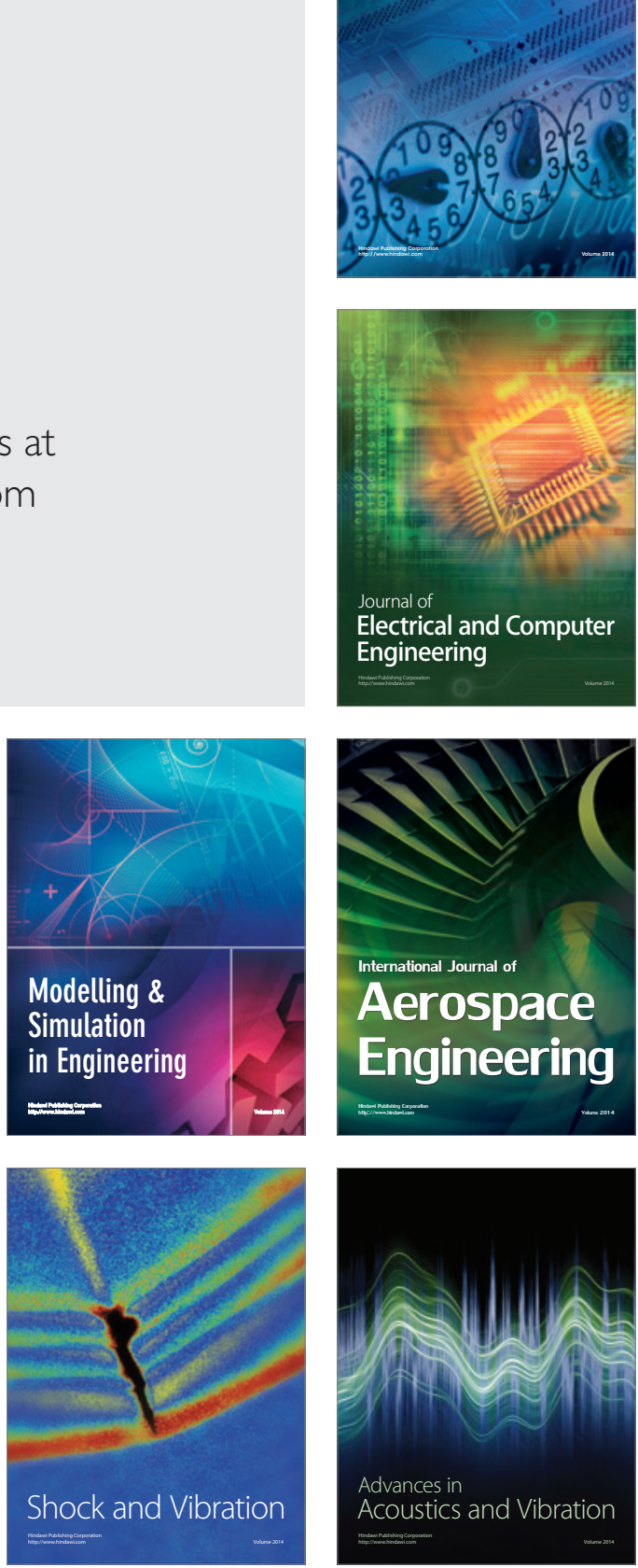